\title{
Radiative and climate effects of stratospheric sulfur geoengineering using seasonally varying injection areas
}

\author{
Anton Laakso ${ }^{1,2}$, Hannele Korhonen ${ }^{3}$, Sami Romakkaniemi ${ }^{1}$, and Harri Kokkola ${ }^{1}$ \\ ${ }^{1}$ Finnish Meteorological Institute, Atmospheric Research Centre of Eastern Finland, Kuopio, 70200, Finland \\ ${ }^{2}$ Department of Soil, Water and Climate, University of Minnesota, Twin Cities, St. Paul, MN 55108, USA \\ ${ }^{3}$ Finnish Meteorological Institute, Climate Research, Helsinki, 00100, Finland \\ Correspondence to: Anton Laakso (anton.laakso@fmi.fi)
}

Received: 3 February 2017 - Discussion started: 7 February 2017

Revised: 7 May 2017 - Accepted: 8 May 2017 - Published: 14 June 2017

\begin{abstract}
Stratospheric sulfur injections have often been suggested as a cost-effective geoengineering method to prevent or slow down global warming. In geoengineering studies, these injections are commonly targeted to the Equator, where the yearly mean intensity of the solar radiation is the highest and from where the aerosols disperse globally due to the Brewer-Dobson Circulation. However, compensating for greenhouse gas-induced zonal warming by reducing solar radiation would require a relatively larger radiative forcing to the mid- and high latitudes and a lower forcing to the low latitudes than what is achieved by continuous equatorial injections. In this study we employ alternative aerosol injection scenarios to investigate if the resulting radiative forcing can be targeted to be zonally more uniform without decreasing the global the mean radiative forcing of stratospheric sulfur geoengineering. We used a global aerosol-climate model together with an Earth system model to study the radiative and climate effects of stratospheric sulfur injection scenarios with different injection areas. According to our simulations, varying the $\mathrm{SO}_{2}$ injection area seasonally would result in a similar global mean cooling effect as injecting $\mathrm{SO}_{2}$ to the Equator, but with a more uniform zonal distribution of shortwave radiative forcing. Compared to the case of equatorial injections, in the seasonally varying injection scenario where the maximum sulfur production from injected $\mathrm{SO}_{2}$ followed the maximum of solar radiation, the shortwave radiative forcing decreased by $27 \%$ over the Equator (the latitudes between $20^{\circ} \mathrm{N}$ and $20^{\circ} \mathrm{S}$ ) and increased by $15 \%$ over higher latitudes. Compared to the continuous injections to the Equator, in summer months the radiative forcing was increased by 17 and $14 \%$ and in winter months decreased by
\end{abstract}

14 and $16 \%$ in Northern and Southern hemispheres, respectively. However, these forcings do not translate into as large changes in temperatures. The changes in forcing would only lead to $0.05 \mathrm{~K}$ warmer winters and $0.05 \mathrm{~K}$ cooler summers in the Northern Hemisphere, which is roughly $3 \%$ of the cooling resulting from solar radiation management scenarios studied here.

\section{Introduction}

Solar radiation management (SRM) by increasing the atmospheric aerosol particle concentration has been shown to have the potential to counteract at least some of the ongoing global warming, and has therefore been considered a possible option to reduce the risks of climate change caused by increased greenhouse gas concentration in the atmosphere (Royal Society, 2009). One of the proposed methods is to produce sulfate particles into the stratosphere, where they reflect solar radiation back to space and thus cool the surface climate. It has been suggested that sulfur for geoengineering purposes could be injected as $\mathrm{SO}_{2}$, which is oxidized to $\mathrm{H}_{2} \mathrm{SO}_{4}$ and subsequently forms sulfate particles (Kravitz et al., 2013a; Royal Society, 2009). Because of the stability of the stratosphere and the lack of removal mechanisms, which are prevalent in the troposphere, the stratospheric lifetime of sulfate particles is 1-2 years, which would lead to a longer lasting cooling than aerosol emissions at the surface.

Most previous modeling studies have investigated scenarios that inject sulfur along or close to the Equator. This choice of an injection region is well justified because the Equa- 
tor, on average, receives the highest levels of solar radiation. In addition, the stratospheric circulation transports particles efficiently from the Equator around the global atmosphere (Robock et al., 2008). However, it has been found in several studies that preventing greenhouse gas (GHG)-induced warming by equatorial injections of sulfur would lead to overcooling of the tropics and undercooling of the polar regions, compared to the global mean decrease in temperature (Aswathy et al., 2015; Jones et al., 2010, 2016; Kravitz et al., 2016; McCusker et al., 2012; Yu et al., 2015). This would also lead to a reduced meridional temperature gradient, which, for example, could reduce midlatitude precipitation (Schmidt et al., 2012). Therefore, it is worth investigating whether different spatial injection patterns could lead to more uniform cooling around the globe.

The previous research on this topic has shown that the temperature response would indeed be zonally more uniform if radiative forcing were concentrated to the extra-tropics. These studies have, however, used either a reduced solar constant (MacMartin et al., 2013; Kravitz et al., 2016) or prescribed aerosol fields (Modak and Bala, 2014) to approximate the climate impacts of the stratospheric sulfur injections. While such simplified scenarios are useful for studying the climate response in idealized scenarios and easily be implemented in various climate models, the applied radiative forcing does not necessarily correspond to the forcing that would result from actual stratospheric injections of $\mathrm{SO}_{2}$. This is because a reduced solar constant or prescribed aerosol fields do not account for the transport of gas and particulate phase sulfur in the stratosphere, which impacts the spatial distribution of the sulfate particles. Nor does it takes into account the aerosol microphysics, which can significantly affect the radiative properties and the lifetime of the aerosol population (Heckendorn et al., 2009). Thus, climate model studies using a description of aerosol microphysics and sulfur chemistry are required for more realistic simulations of stratospheric sulfur injection strategies. The only studies where other than equatorial injection were studied by a global aerosol-climate model to date (Robock et al., 2008; Volodin et al., 2011) injected sulfur at high latitudes, which led to a significantly smaller radiative forcing than equatorial injections.

In this study, we have investigated injection scenarios that aim to produce a geographically more even radiative forcing pattern than equatorial sulfur injections, while still maintaining a high global mean forcing. Such scenarios are sought via seasonally varying injection areas in which the injection area follows the maximum solar intensity with different time lags. These scenarios are compared to more commonly used strategies with fixed injection areas. This study should be taken as a first step in evaluating optimal injection strategies in terms of geographically more uniform aerosol fields/radiative forcing/climate impacts without losing the effectiveness of geoengineering compared to continuous equatorial injections. In order to fully optimize the injection strat- egy, one should try to also account for the effect of stratospheric circulation on aerosol transport, together with existing planetary reflectivity and a detailed analysis of aerosol microphysics. These aspects are outside the scope of this study.

The simulations are done in two steps. First, we use the global aerosol-climate model ECHAM-HAMMOZ to investigate the radiative forcing from the zonally different injection areas and to define aerosol fields. Second, the global and regional temperature and precipitation responses are studied using the coupled climate-ocean model MPI-ESM (Max Planck Institute's Earth System Model), which does not include a prognostic calculation of aerosol processes in its current configuration.

\section{Methods}

\subsection{Simulated SRM scenarios}

Eight zonally different sulfur injection strategies were simulated. In all of these scenarios, $5 \mathrm{Tg}(\mathrm{S}) \mathrm{yr}^{-1}$ of gaseous $\mathrm{SO}_{2}$ were injected continuously over the year to the stratosphere at the height of $20 \mathrm{~km}$ and to a $20^{\circ}$ wide latitude band specified below ( 2 bands in one of the simulated scenarios).

\subsubsection{Fixed injection areas}

In three of the studied injection scenarios, the area of continuous sulfur injections remained fixed throughout the year. In scenario Equator (EQ), sulfur was injected over the Equator between latitudes $10^{\circ} \mathrm{N}$ and $10^{\circ} \mathrm{S}$ (Fig. 1a). This injection strategy corresponds to the injection scenarios in most previous studies, although they have used different widths for the injection area (Heckendorn et al., 2009; Jones et al., 2016; Niemeier et al., 2011; Pierce et al., 2010; Pope et al., 2012; Tilmes et al., 2015). In the Northern Hemisphere (NH) scenario, sulfur was injected only in the Northern Hemisphere between latitudes 10 and $30^{\circ} \mathrm{N}$ (Fig. 1b). In scenario NHSH $2.5 \mathrm{Tg}(\mathrm{S}) \mathrm{yr}^{-1}$ sulfur was injected between the Northern Hemisphere between latitudes 10 and $30^{\circ} \mathrm{N}$ and $2.5 \mathrm{Tg}(\mathrm{S}) \mathrm{yr}^{-1}$ and the Southern Hemisphere between latitudes 10 and $30^{\circ} \mathrm{S}$ (Fig. 1c) to reduce the overcooling in the tropics inherent to equatorial injections at the same time aiming at reducing the change in the meridional temperature gradient compared to the scenario EQ. However, NH and NHSH are expected to result in a smaller global cooling effect than EQ because the resulting distribution of aerosols is concentrated to the injection area and at latitudes where the annual mean solar radiation is smaller than over the Equator.

\subsubsection{Seasonally changing injection areas}

In addition to the abovementioned scenarios, five scenarios where the sulfate injection area is varied throughout the year were simulated. In four of these scenarios, the $20^{\circ}$ wide 

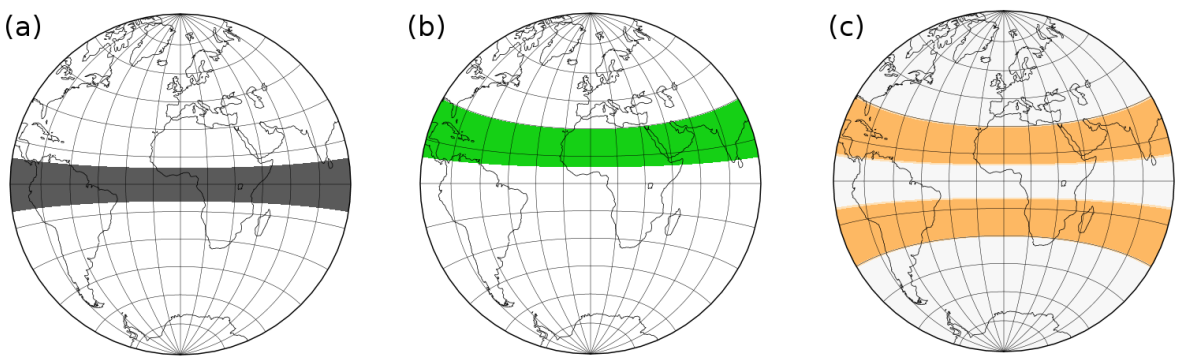

Figure 1. Injection areas in scenarios (a) EQ, (b) NH and (c) NHSH.

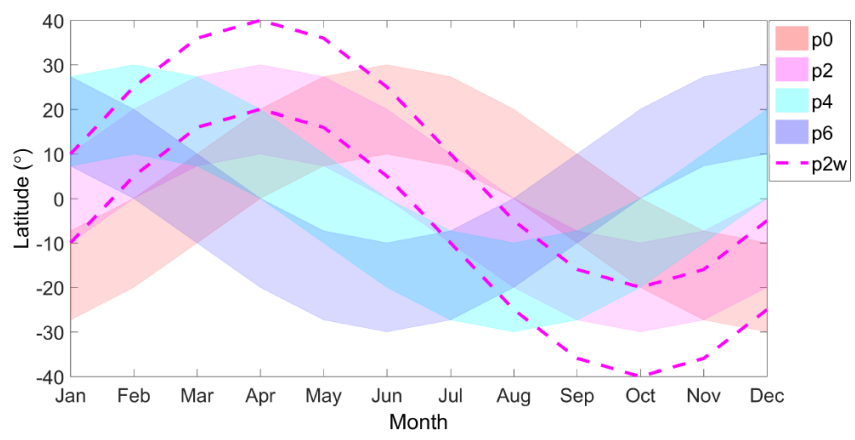

Figure 2. Seasonally changing injection areas in p0, p2, p4, p6 and p2w scenarios.

sulfur injection area changed monthly between the latitudes $30^{\circ} \mathrm{S}-30^{\circ} \mathrm{N}$ in different phases. In the p0 scenario, the injection area was set to follow the maximum intensity of solar radiation (Fig. 2). Therefore, the sulfur injection area is at its northernmost position $\left(30\right.$ to $10^{\circ} \mathrm{N}$ ) in June coinciding with the location of the NH scenario. In March and September, the center of the injection area is at the Equator, thus coinciding with the injection area of the EQ scenario. The injections are at their southernmost location between 30 to $10^{\circ} \mathrm{S}$ in December.

However, sulfur injected as $\mathrm{SO}_{2}$ takes weeks to months before it is oxidized and forms large enough particles to reflect solar radiation efficiently. Thus, to obtain maximum aerosol forcing, one strategy could be to inject sulfur before the intensity of solar radiation has reached its maximum value at the injection latitude, thus leaving enough time for oxidation and particle growth. However, if sulfur was injected too early, $\mathrm{SO}_{2}$ and formatted sulfate particles would be already transported to the higher latitudes when the intensity of the solar radiation starts to increase. To test this strategy, we repeated $\mathrm{p} 0$ with different temporal phases of the injection area change. In the $\mathrm{p} 2$ scenario, the northernmost injection area is reached in April, 2 months earlier than in the p0 scenario. In the p4 scenario, the northernmost injection area is reached in February and in $\mathrm{p} 6$ in December. Based on the oxidation time of $\mathrm{SO}_{2}, \mathrm{p} 4$ and $\mathrm{p} 6$ scenarios are expected to lead to a smaller radiative forcing than $\mathrm{p} 2$. However, these scenarios are sim- ulated to study how different phase of the changing injection area alters the radiative forcing. Injection areas in these scenarios are presented in Fig. 2. Based on the model simulations with ECHAM-HAMMOZ in Laakso et al. (2016), in the case of Pinatubo eruption, $75 \%$ of the erupted $\mathrm{SO}_{2}$ was oxidized after the first 2 months from the eruption. In these simulations, the global mean radiative forcing of aerosols was also at its largest roughly at the same time. Thus, it could be expected that scenario $\mathrm{p} 2$ would lead to a stronger global mean radiative forcing than the other scenarios studied. To test the impact of concentrating the radiative forcing to even higher latitudes, simulation $\mathrm{p} 2$ was repeated so that the latitude range for the monthly shifting injection area was wider. In this $\mathrm{p} 2 \mathrm{w}$ scenario, the phase and the injection areas is as wide as in p2 (20 in latitudinal direction), but the northernmost location of the injection area in April is between 40 and $20^{\circ} \mathrm{N}$ and southernmost in October between 20 and $40^{\circ} \mathrm{S}$.

\subsection{Model description}

The model simulations were done in two steps: first, the different injection strategies described in Sect. 2.1 were simulated with the global aerosol-climate model ECHAMHAMMOZ that contains an explicit description of $\mathrm{SO}_{2}$ oxidation chemistry as well as aerosol microphysics. These simulations were used to calculate the radiative forcing resulting from the stratospheric injections, as well as to provide the optical properties of stratospheric aerosol fields for the MPI-ESM simulations in step two. Second, the coupled earth system model MPI-ESM was used to the simulate temperature and precipitation effects of stratospheric sulfur injection strategies against the Representative Concentration Pathway 4.5 (RCP4.5, Moss et al., 2010; van Vuuren et al., 2011). The two step approach was selected because the currently available configuration of MPI-ESM does not include a prognostic calculation of aerosol processes. In addition, modeling aerosol microphysics is computationally heavy. Thus, it was feasible to simulate aerosol microphysics only for a relatively short period (few years) and use the ECHAMHAMMOZ simulated aerosol fields as prescribed fields in the longer simulations in MPI-ESM. Simulations with ECHAMHAMMOZ were carried out using a free-running setup to include the dynamical feedbacks resulting from the addi- 
tional heating due to absorption of radiation by the injected aerosols. However, stratospheric circulation could also be altered by changes in the atmospheric GHG concentration (in our case following the RCP4.5 scenario) and its impacts on the tropospheric climate; however, these impacts were not taken into account when the aerosol fields were calculated in ECHAM-HAMMOZ.

\subsubsection{Defining aerosol fields using ECHAM-HAMMOZ}

The radiative properties of aerosol fields resulting from the $5 \mathrm{Tg}(\mathrm{S}) \mathrm{yr}^{-1}$ stratospheric sulfur injections were defined by using the global aerosol-climate model MAECHAM6.1HAM2.2-SALSA (Zhang et al., 2012; the middle atmosphere configuration of the European Centre Hamburg Model coupled with Hamburg Aerosol Model including a Sectional Aerosol module for Large-Scale Applications). The model has been shown to simulate the stratospheric aerosol loads and radiative properties consistently compared to the observations of the Mt. Pinatubo 1991 eruption as well as other models (Laakso et al., 2016). In total, 9-year-long simulations were performed for each of the scenarios. The simulations started in conditions without SRM and included a 2-year ramp-up period where continuous $\mathrm{SO}_{2}$ injection was started $\left(5 \operatorname{Tg}(\mathrm{S}) \mathrm{yr}^{-1}\right)$. This 2-year ramp-up was long enough for the formation of a steady-state stratospheric sulfate field where in average the same amount of sulfur is removed from the atmosphere as was injected. The ramp-up period was followed by a 5-year steady-state period during which the sulfur field was maintained by continuous $5 \mathrm{Tg}(\mathrm{S}) \mathrm{yr}^{-1}$ injections. Furthermore, two additional years were run to simulate the suspension of solar radiation management. In the beginning of this ramp-down period the sulfur injections were suspended. After 2 years, sulfate particles from the injections are removed from the atmosphere.

For further analysis, the radiative forcings and stratospheric sulfur burdens were calculated as 5-year mean values over the steady-state period and compared to the CTRL simulation, which included only standard tropospheric emissions (see below). Furthermore, for the climate simulations, the radiative properties of the aerosol fields were calculated and implemented in MPI-ESM as monthly means.

Simulations were performed with a T63L47 resolution, which corresponds approximately to a $1.9^{\circ} \times 1.9^{\circ}$ horizontal grid and in which the atmosphere is divided into 47 height levels reaching up to $\sim 80 \mathrm{~km}$. The aerosol module HAM is coupled interactively to ECHAM and includes an explicit sectional aerosol scheme SALSA (Bergman et al., 2012; Kokkola et al., 2008; Laakso et al., 2016), which calculates the microphysical processes of nucleation, condensation, coagulation and hydration. In the SALSA configuration used, aerosols are described by aerosol number and volume size distributions with 10 size sections for internally and 7 size sections for externally mixed particles (see Laakso et al., 2016, for details). The HAM module calculates the aerosol emissions, removal, gas and liquid phase chemistry, and the radiative properties for the major global aerosol compounds of sulfate, organic carbon, black carbon, sea salt and mineral dust. Aerocom II (Aerosol Comparisons between Observations and Models) tropospheric emissions for year 2010 were used in all simulations (Dentener et al., 2006). The model contains an explicit description of sulfur dioxide oxidation chemistry (Feichter et al., 1996). The hydroxyl radical $(\mathrm{OH})$ and ozone concentrations are accounted for through prescribed monthly mean fields. Thus, the effect of sulfur injections on the ozone layer is not simulated in our model. The ECHAM-HAMMOZ simulations were done using CMIP5 (Coupled Model Intercomparison Project) AMIP2 (Aerosol Chemistry Climate Model Intercomparison Project) climatological sea surface temperatures and sea ice distributions, which are derived as a mean values between years 1979 and 2008 (Taylor et al., 2008).

\subsubsection{Simulating climate effects using MPI-ESM}

To study the climate effects of the different stratospheric sulfur injection scenarios, we used the Max Planck Institute's Earth system model (MPI-ESM; (Giorgetta et al., 2013). The model is a state-of-the-art coupled three-dimensional atmosphere-ocean-land surface model. The model consists of the atmospheric component ECHAM6.1 (Stevens et al., 2013), which is fully coupled to the Max Planck Institute Ocean Model (MPIOM; Junglaus et al., 2013). MPIESM also includes active components of the land model JSBACH (Reick et al., 2013) and the ocean biochemistry model HAMOCC (Ilyina et al., 2013). However, atmospheric GHG concentrations follow the RCP 4.5 scenario (Moss et al., 2010; van Vuuren et al., 2011).

In this study, global fields of radiative properties of stratospheric aerosol from ECHAM-HAMMOZ simulations were implemented to MPI-ESM. The aerosol optical depth, single scattering albedo and asymmetry factor for the stratospheric aerosol field were first calculated for 30 wavelength bands using ECHAM-HAMMOZ and then used as an input for MPI-ESM. The implementation method used here is an improvement to that presented by Laakso et al. (2016), where the aerosol radiative properties in MPI-ESM were calculated based on a single modal size distribution with a fixed mode width and monthly mean values of aerosol effective radius and aerosol optical depth (AOD) at $550 \mathrm{~nm}$ resulting from simulations with ECHAM-HAMMOZ. Thus, particle size distribution in MPI-ESM was described by single mode, which did not correspond to the sectional size distribution in ECHAM-HAMMOZ. This led to a slightly different aerosol radiative forcing in MPI-ESM than what was calculated by ECHAM-HAMMOZ (Laakso et al., 2016). In the current study the only difference in the stratospheric aerosol radiative properties between ECHAM-HAMMOZ and MPI-ESM is that in MPI-ESM simulations the stratospheric aerosol fields are described as zonal monthly mean values. This difference 
Table 1. The 5-year mean values of the global stratospheric sulfur dioxide and particulate sulfate burdens and the global shortwave (SW) all-sky forcing. In studied scenarios $5 \mathrm{Tg}(\mathrm{S})$ of sulfur is injected continuously in latitudes showed in Figs. 1 and 2.

\begin{tabular}{lrrr}
\hline Scenario & $\begin{array}{r}\text { Strat. } \mathrm{SO}_{2} \text { burden } \\
\operatorname{Tg}(\mathrm{S})\end{array}$ & $\begin{array}{r}\text { Strat. } \mathrm{H}_{2} \mathrm{SO}_{4} \text { burden } \\
\operatorname{Tg}(\mathrm{S})\end{array}$ & $\begin{array}{r}\text { All-sky SW forcing at TOA } \\
\left(\mathrm{W} \mathrm{m}^{-2}\right)\end{array}$ \\
\hline $\mathrm{EQ}$ & 0.69 & 6.15 & -3.72 \\
$\mathrm{NH}$ & 0.80 & 5.46 & -3.21 \\
$\mathrm{NHSH}$ & 0.79 & 5.66 & -3.30 \\
p0 & 0.64 & 6.15 & -3.67 \\
p2 & 0.66 & 6.28 & -3.82 \\
p4 & 0.75 & 6.18 & -3.74 \\
p6 & 0.84 & 5.98 & -3.58 \\
p2w & 0.68 & 6.29 & -3.72 \\
\hline
\end{tabular}

is not expected to affect the results significantly; however, the chosen approach keeps the size of the aerosol input files for MPI-ESM manageable. To describe the properties of the tropospheric aerosol in MPI-ESM, we used the tropospheric aerosol climatology of Kinne et al. (2013) in all simulations.

In the climate simulations with MPI-ESM, our setup of scenarios was similar to the Geoengineering Model Intercomparison Project (GeoMIP) G4 scenario (Kravitz et al., 2011, 2013a); however, in our study $5 \mathrm{Tg}(\mathrm{S}) \mathrm{yr}^{-1}$ is injected instead of $2.5 \mathrm{Tg}(\mathrm{S}) \mathrm{yr}^{-1}$ to get stronger climate signal. As with GeoMIP, we started our simulations from year 2010 and continued until 2100. The baseline scenario with no SRM followed the RCP 4.5 scenario. All SRM scenarios also included the RCP4.5 tropospheric emissions but they also included additional stratospheric sulfur injections starting in year 2020. The sulfur injections were applied for 50 years and then suspended. After that, the simulations were continued for 30 years until year 2100 to simulate the termination effect of geoengineering (Jones et al., 2013; Kravitz et al., 2011). The emerging stratospheric sulfur field in the 2year ramp-up period simulated by ECHAM-HAMMOZ was used in MPI-ESM for years 2020-2021. The ramp-down period sulfur field, when sulfur injections are suspended and sulfate particles are removed from the atmosphere, was used for years 2070-2071. Between the ramp-up and ramp-down periods (2022-2070) steady-state stratospheric sulfur field from $5 \mathrm{Tg}(\mathrm{S}) \mathrm{yr}^{-1}$ injection from simulations with ECHAMHAMMOZ were used.

\section{Results}

\subsection{Atmosphere-only simulations using ECHAM-HAMMOZ}

In this section we investigate the radiative forcing resulting from the aerosol microphysical simulations of different injection scenarios. When talking about the changes in the aerosol shortwave (SW) radiative forcings (which are typically negative), we have applied a commonly used and intu- itively clear convention: decrease in the forcing refers to the numerical value of the forcing getting closer to zero (i.e., in strictly mathematical sense increasing); similarly, an increase in forcing refers to the numerical value becoming more negative.

\subsubsection{Radiative forcing of alternative injection scenarios}

Table 1 shows the global $\mathrm{SO}_{2}$ and sulfate burdens and the global mean all-sky shortwave (SW) radiative forcing in the studied sulfur injection scenarios. The baseline EQ scenario leads to an all-sky SW radiative forcing of $-3.72 \mathrm{~W} \mathrm{~m}^{-2}$. As expected, both $\mathrm{NH}$ and $\mathrm{NHSH}$ scenarios give clearly smaller radiative impacts $\left(-3.21\right.$ and $-3.30 \mathrm{~W} \mathrm{~m}^{-2}$, respectively) than EQ. This is because in these two scenarios sulfur is injected to an area where the solar intensity is on the average weaker and from where the Brewer-Dobson Circulation transports sulfur mainly towards higher latitudes (Robock et al., 2008). Further contributing to the smaller forcing in $\mathrm{NH}$ and NHSH is the fact that the lifetime of stratospheric sulfur is longer when injected to the Equator (Robock et al., 2008).

Scenarios NH and NHSH produce somewhat different global mean SW radiative forcings as well as stratospheric $\mathrm{SO}_{2}$ and sulfate burdens even though in both cases the sulfur is injected in regions with equal distances from the Equator. The difference between these two scenarios is that in scenario $\mathrm{NH}$, the same amount of sulfur is injected to a smaller total area than in NHSH. Previous research has shown that higher injections per unit volume lead to relatively larger particles, which in turn leads to a relatively shorter lifetime of particles in the atmosphere (Heckendorn et al., 2009; English et al., 2012; Niemeier et al., 2011). Thus, the particle effective radius is clearly smaller in scenario NHSH than in scenario $\mathrm{NH}$, especially in the Northern Hemisphere (Fig. 3). The forcing in the $\mathrm{NH}$ scenario is further reduced compared to NHSH by the fact that the Earth's surface albedo is higher in the Northern Hemisphere than in the Southern Hemisphere.

The global burdens and mean forcings in the scenarios with seasonally changing sulfur injection area $(\mathrm{p} 0, \mathrm{p} 2, \mathrm{p} 4$, 

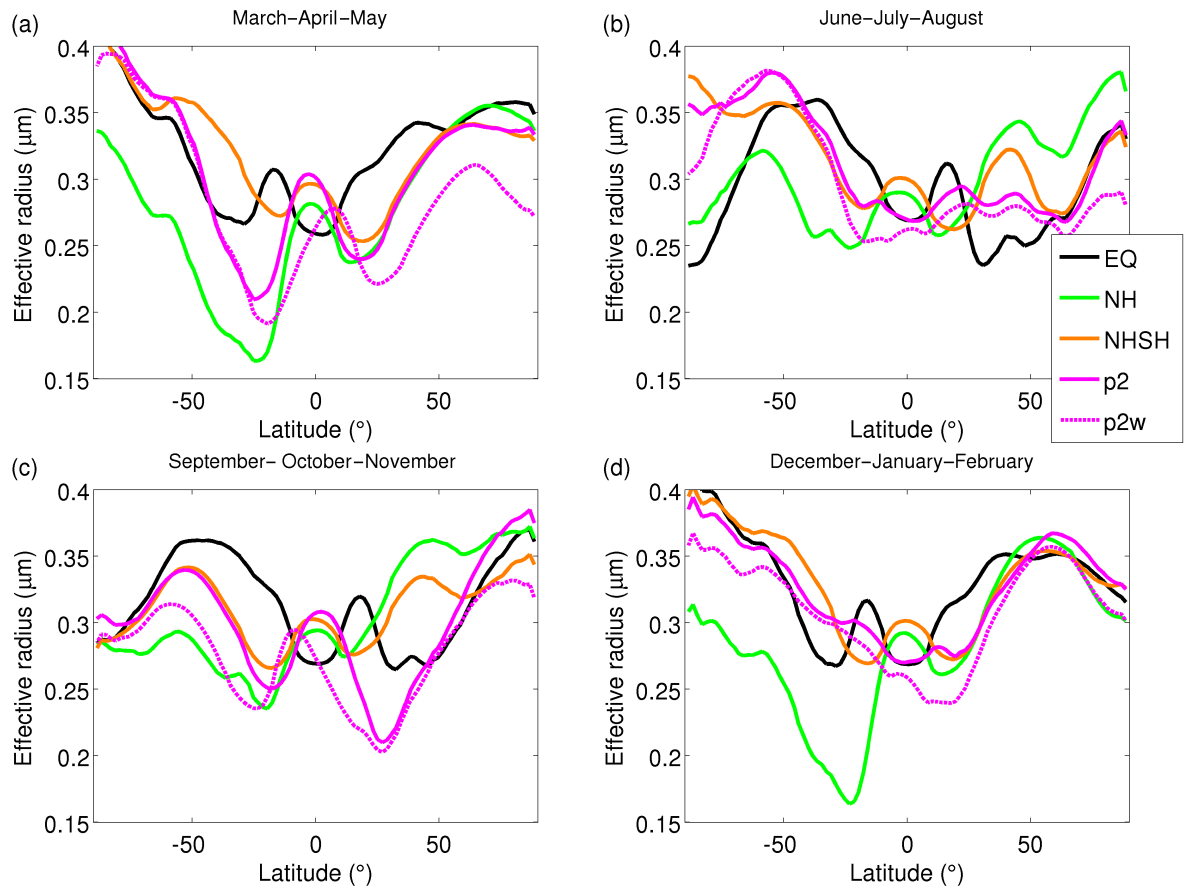

Figure 3. The zonal mean effective radius of the stratospheric particles in (a) March-April-May, (b) June-July-August, (c) SeptemberOctober-November and (d) December-January-February.

p6) are quite close to those in the EQ scenario (Table 1). However, out of all the scenarios the largest radiative forcing of $-3.82 \mathrm{~W} \mathrm{~m}^{-2}$ (i.e., $0.1 \mathrm{~W} \mathrm{~m}^{-2}$ larger than in $\mathrm{EQ}$ ) is simulated in scenario $\mathrm{p} 2$. When the injection area is varied throughout the year in a well-timed phase, the reflective sulfate particles are on the average concentrated in latitudes with larger solar intensity than if sulfur is injected only to the EQ. It can be expected that the difference in the global mean radiative forcing between scenarios EQ and $\mathrm{p} 2$ would increase even more if a larger amount of sulfur were injected, because of a sub-linear correlation between the amount of annual sulfur injections and the radiative forcing (Heckendorn et al., 2009). Such losses are slower when the injection area is varied and thus the injection per unit volume of air is smaller, and thus more newly formed particles survive to become large enough to scatter radiation efficiently. As a result, the number concentration of smaller particles increases. Figure 3 shows that the particle effective radius is on average smaller in scenario $\mathrm{p} 2$ than in EQ.

Based on the scenarios used here, to achieve maximum aerosol forcing the varying sulfur injection area should reach its northernmost location 2 months (April) earlier (p2) than the solar radiation reaches its maximum (June). This way, the formed particles from the $\mathrm{SO}_{2}$ injection reach the optimal size at the time of maximum solar radiation. On the other hand, in p0 and p6 scenarios the seasonality of the solar radiation intensity and its impacts on the seasonality of hydroxyl radical $(\mathrm{OH})$ concentration lead to a lower global forcing than in most other scenarios (EQ, p2, p4, p2w). This is because $\mathrm{OH}$ is the main oxidant that converts $\mathrm{SO}_{2}$ to sulfuric acid $\left(\mathrm{H}_{2} \mathrm{SO}_{4}\right)$, which together with $\mathrm{H}_{2} \mathrm{O}$ molecules nucleate and grow the stratospheric aerosol particles. In the p0 scenario, the $\mathrm{SO}_{2}$ injection area follows the area that receives the highest amount of solar radiation. These latitudes have a high $\mathrm{OH}$ concentration, which leads to faster oxidation than in other scenarios, as can be seen from the smallest $\mathrm{SO}_{2}$ burden in Table 1. However, it takes a couple of months before the formed particles have grown large enough to reflect solar radiation effectively, and by the time this happens, the solar intensity has already decreased at the latitudes where the particulate sulfur burden has increased the most. On the other hand, in $\mathrm{p} 6$ sulfur is injected always during the months when the injection region experiences its lowest annual solar radiation. This leads to a relatively slow oxidation rate, as can be seen from the large $\mathrm{SO}_{2}$ burden. However, because of the lifetime of sulfate particles is over 1 year, most of the injected sulfur is still in the atmosphere in the summer around 6 months after the injection, and thus the global mean radiative forcing is not significantly smaller than in the other scenarios. In addition, here sulfur is injected in all p0, p2, p4 and p6 scenarios to the low latitudes (between $30^{\circ} \mathrm{N}$ and $30^{\circ} \mathrm{S}$ ), which receive high solar radiation throughout the year. Thus, considerably large differences in the global yearly mean radiative forcing between the scenarios are not expected.

Finally, in p $2 \mathrm{w}$ the injection area changes between $40^{\circ} \mathrm{N}$ and $40^{\circ} \mathrm{S}$ instead of $30^{\circ} \mathrm{N}$ and $30^{\circ} \mathrm{S}$. Because sulfur is in- 
jected at a larger distance from the Equator than in $\mathrm{p} 2$, the global mean all-sky shortwave radiative forcing is $3 \%$ $\left(0.1 \mathrm{~W} \mathrm{~m}^{-2}\right)$ smaller than in $\mathrm{p} 2$ (Table 1). Figure 3 shows that in scenario $\mathrm{p} 2 \mathrm{w}$ particles are consistently smaller than in $\mathrm{p} 2$. However, due to the atmospheric circulation, which transports particles mainly towards the poles, in scenario $\mathrm{p} 2 \mathrm{w}$ particles are removed more quickly from the atmosphere because sulfur is injected at a larger distance from the Equator. In addition, the tropopause height varies with latitude and when injecting sulfur to higher latitudes in $\mathrm{p} 2 \mathrm{w}$ scenario, some of the sulfur is injected into the upper branch of the stratospheric circulation. Overall there is no difference in stratospheric sulfur burden between $\mathrm{p} 2$ and $\mathrm{p} 2 \mathrm{w}$ scenarios (Table 1). While the all-sky forcing is as large as in EQ (Table 1), the clear-sky forcing is $0.16 \mathrm{~W} \mathrm{~m}^{-2}$ larger in scenario $\mathrm{p} 2 \mathrm{w}$ than in scenario EQ $\left(5.76\right.$ and $5.60 \mathrm{~W} \mathrm{~m}^{-2}$, respectively). This is because in scenario $\mathrm{p} 2 \mathrm{w}$ more sulfur resides in the midlatitudes $\left(40-60^{\circ}\right)$ where the cloud cover is larger than in the low latitudes and therefore the original albedo is larger. This decreases the all-sky radiative forcing of $\mathrm{p} 2 \mathrm{w}$ compared to EQ.

Overall the results show that extending the injection area to the midlatitudes for a part of the year can, in terms of the global forcing, be as effective as the injections to the Equator if the injection area is changed in a certain phase. However, the zonal differences between these two injection strategies can be very different, as will be illustrated in the following.

Figure 4 shows the 5-year zonal mean shortwave radiative forcing in $\mathrm{EQ}, \mathrm{NH}, \mathrm{NHSH}, \mathrm{p} 2$ and $\mathrm{p} 2 \mathrm{w}$ scenarios. As expected, scenario EQ (black line) leads to the strongest radiative forcing at the Equator; however, outside the tropics the forcing declines fast (EQ) as seen also in the case of equatorial injection in Niemeier et al. (2011). In the p2 (pink solid line) and $\mathrm{p} 2 \mathrm{w}$ (pink dashed line) scenarios the forcing is distributed much more evenly throughout the tropics and the midlatitudes. Compared to EQ, p2 shows $7 \%$ lower mean forcing between $20^{\circ} \mathrm{N}$ and $20^{\circ} \mathrm{S}$ but $10 \%$ larger forcing in higher latitudes. The difference between $\mathrm{p} 2 \mathrm{w}$ and EQ is even larger: $27 \%$ between $20^{\circ} \mathrm{S}$ and $20^{\circ} \mathrm{N}$ and $15 \%$ in the higher latitudes. Thus, these results show that by varying the injection area it would be possible to obtain a more evenly distributed zonal forcing or even concentrate the maximum forcing to midlatitudes, while achieving similar or even larger global mean radiative forcing than in scenario EQ. This could prevent some of the decrease of the meridional temperature gradient due to geoengineering and GHG-induced warming.

While the scenario NHSH (orange line) also leads to a relatively evenly distributed zonal forcing in most latitudes, the total global forcing is clearly lower than in the case of EQ, p2 and $\mathrm{p} 2 \mathrm{w}$ scenarios (Table 1). In scenario NH (green line), the forcing is concentrated mainly to the Northern Hemisphere $\left(-4.42 \mathrm{~W} \mathrm{~m}^{-2}\right)$. There is also a moderate radiative forcing in the Southern Hemisphere $\left(-2.00 \mathrm{~W} \mathrm{~m}^{-2}\right)$.

Further insight into the different zonal and global radiative effects between the scenarios can be obtained from Fig. 5,

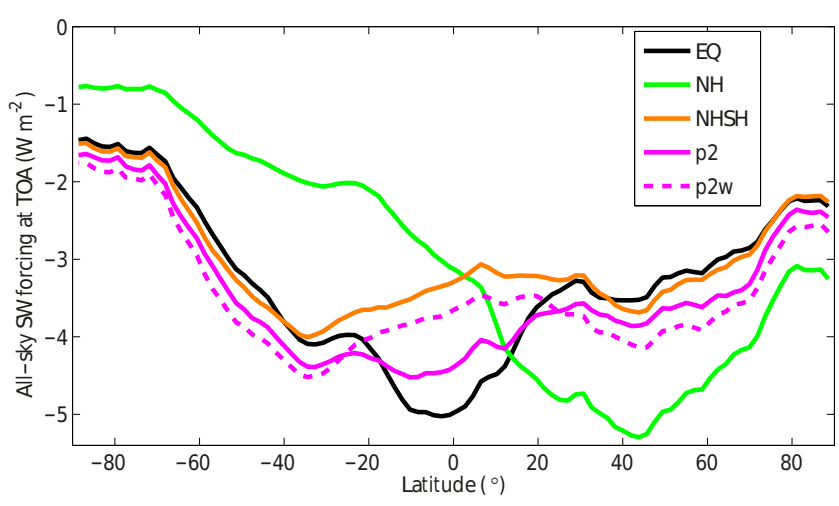

Figure 4. The 5-year zonal means of all-sky shortwave radiative forcing in selected scenarios.

which shows the burden of stratospheric sulfate particles and the zonal distribution of the incoming solar radiation (shown in orange in the figure), in boreal winter (DJF) (Fig. 5a) and summer (JJA) (Fig. 5b). Sulfate burden and solar radiation are shown per meter in meridional direction. Thus, the different length of the circumference along an individual latitude is taken account in the figure.

In the depicted seasons, the maximum solar radiation is received about $15^{\circ}$ south or north of the Equator. In scenario $\mathrm{EQ}$, sulfate is concentrated near the injection area in Equator and near the $50^{\circ} \mathrm{N}$ and $50^{\circ} \mathrm{S}$ latitudes as shown in earlier studies (English et al., 2012; Jones et al., 2016; Niemeier et al., 2011). Thus, in scenario EQ, much of the zonal sulfate burden peaks around the Equator being less than optimally located (black line) with respect to the incoming radiation. In addition, the meridional wind component over the Equator $\left(10^{\circ} \mathrm{N}-10^{\circ} \mathrm{S}\right)$ in the stratosphere $(20-25 \mathrm{~km}$ altitude) is on the average towards the north in the northern autumn and towards the south in the northern spring. Thus, there is more sulfate in scenario EQ in the midlatitudes of the winter hemisphere, which gets significantly less solar radiation than the summer hemisphere. Thus, when the sulfate particles are concentrated to the winter hemisphere, they reflect less solar radiation making solar radiation management less efficient. On the other hand, in the p2 scenario, the maximum of zonal mean sulfur burden is roughly at the same latitudes as the maximum solar radiation and, compared to scenario $\mathrm{EQ}$, more sulfate is in the summer hemisphere. This leads to a larger radiative effect in scenario $\mathrm{p} 2$ than in scenario EQ during the summer months and but also to a smaller radiative effect in the winter months, as can be seen Fig. $5 \mathrm{c}$ and d. Compared to scenario EQ, the total-sky SW radiative forcing in scenario $\mathrm{p} 2$ is $15 \%$ larger in the boreal summer months and $15 \%$ smaller in the winter months in the Northern Hemisphere. The difference can be seen especially in high latitudes (north of $50^{\circ} \mathrm{N}$ ), where the mean radiative forcing is $23 \%$ larger in p2 than in EQ in June-July-August (not shown). On the other hand, compared to scenario EQ, 

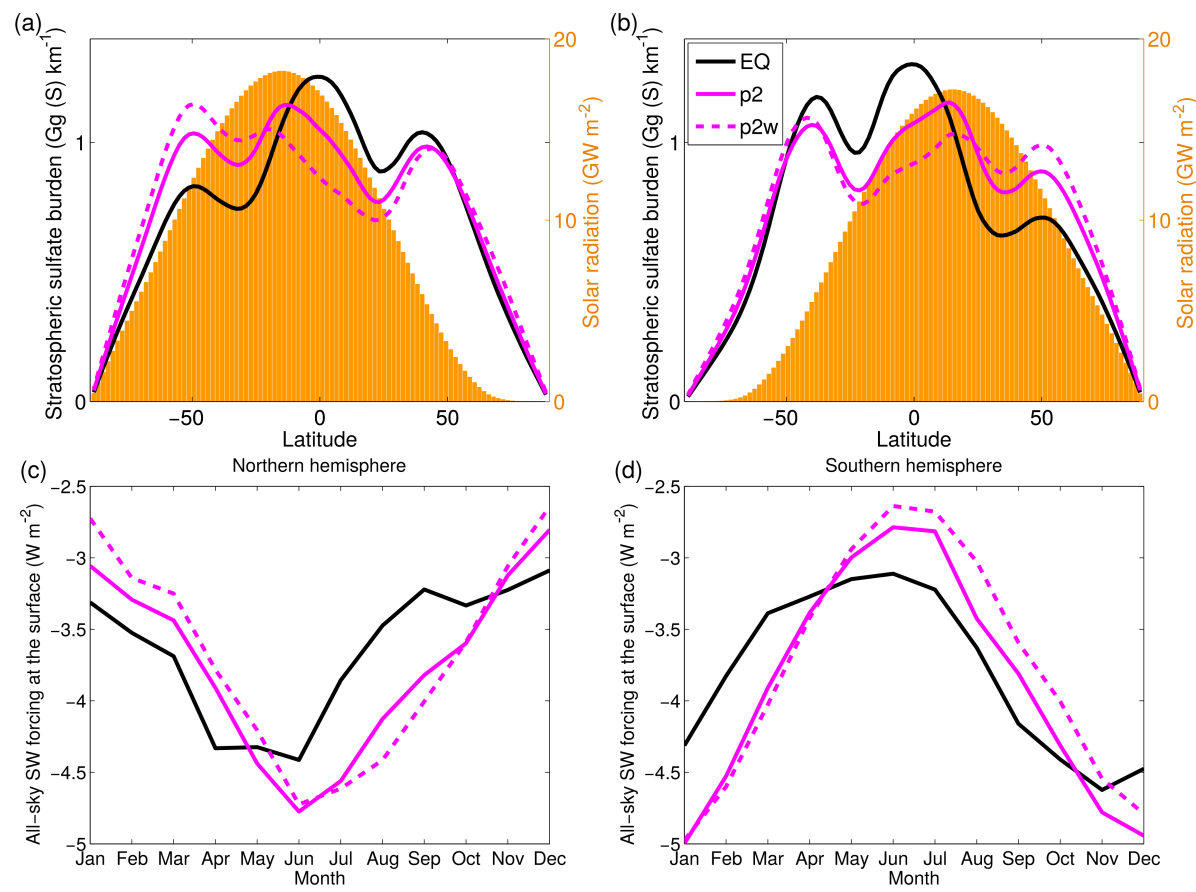

Figure 5. The zonal distribution of stratospheric particulate sulfate burden and the zonally distributed incoming solar radiation in the (a) December-January-February and (b) June-July-August and the all-sky shortwave radiative forcing at (c) the Northern Hemisphere and (d) the Southern Hemisphere. In panels $(\mathbf{a}, \mathbf{b})$ sulfate burden and solar radiation are shown per meridional meter.

scenario $\mathrm{p} 2 \mathrm{w}$ leads to 17 and $14 \%$ larger radiative forcing in the summer months over the Northern and Southern hemispheres, respectively. In winter months the radiative forcing is -14 and $-16 \%$ lower in the Northern and Southern hemispheres respectively compared to scenario EQ.

\subsubsection{Aerosol optical depth (AOD), solar radiation and stratospheric circulation}

In this study the choice of the injection strategy was based only on the seasonality of the solar radiation. However, more optimal strategies, for example, for achieving the strongest global radiative forcing of geoengineering or achieving the maximum cooling for specific latitudes, would require a more specific investigation. The aerosol radiative effects would also depend on, e.g., the size and the optical properties of the particles as well as on the stratospheric circulation and how it will change due to the dynamical feedback caused by the injected sulfur. Figure 6a-e show the zonal mean $533 \mathrm{~nm}$ wavelength AOD of stratospheric particles at different times of the year. Figure 6f shows the meridional zonal mean wind component, which indicates how injected sulfur transports in the atmosphere. The wind component is calculated at the height of the maximum AOD. The height was calculated based on scenario EQ but was the same in the other studied scenarios. The height of the AOD maximum was laying above the tropopause and was roughly at
$20-21 \mathrm{~km}$ height over the tropics and decreased over the midlatitudes to $15 \mathrm{~km}$ over the high latitudes.

In the case of equatorial injections, the AOD is clearly larger close to the Equator and in high latitudes than in midlatitudes (Fig. 6a). This is consistent with earlier studies (English et al., 2012; Jones et al., 2016; Niemeier et al., 2011). Because of stratospheric circulation (Fig. 6f), AOD is clearly smaller at subtropics $\left(10-30^{\circ}\right)$ in all of the studied scenarios. This happens also in the scenarios where sulfur was injected continuously to subtropics (scenarios NH and NHSH, boundaries of injection area shown by blue lines) and the AOD at the subtropics was lower than in higher latitudes. Especially during the boreal winter, the strong stratospheric winds (Fig. 6f) transport particles farther north.

The hatched area in Fig. 6 shows the latitudes that receive over $50 \%$ of the monthly solar radiation. In scenario p 2 the tropical high AOD values reside over this area more often than in the other scenarios. The high AOD combined with the large solar intensity in these latitudes led to the largest global mean radiative forcing in scenario $\mathrm{p} 2$ compared to the other studied scenarios. As was the intention of this scenario, it led to smaller AOD in the Equator and higher AOD in higher latitudes, especially in the summer months, compared to scenario EQ. In scenario p2w AOD was larger in the high latitudes and smaller in the tropical area than scenario p2. The subtropical AOD was the largest in the late summer months. In the late winter months and spring months, the injection area was located to latitudes where the strong winds to po- 
(a)

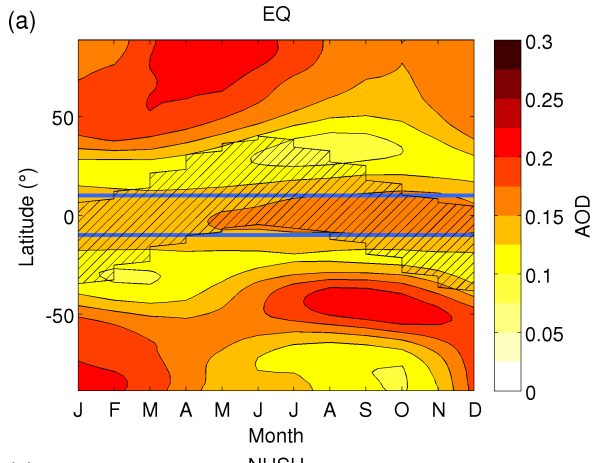

(c)

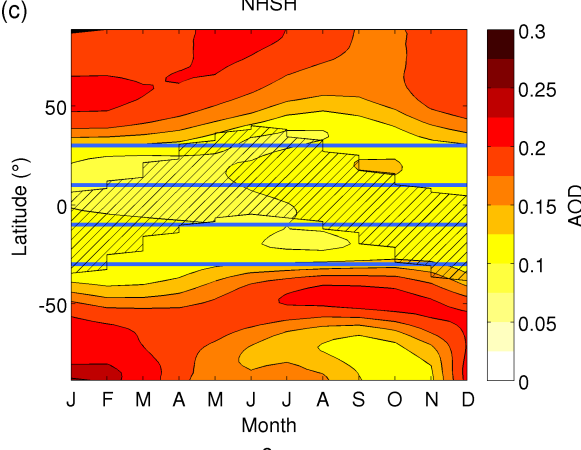

(e)

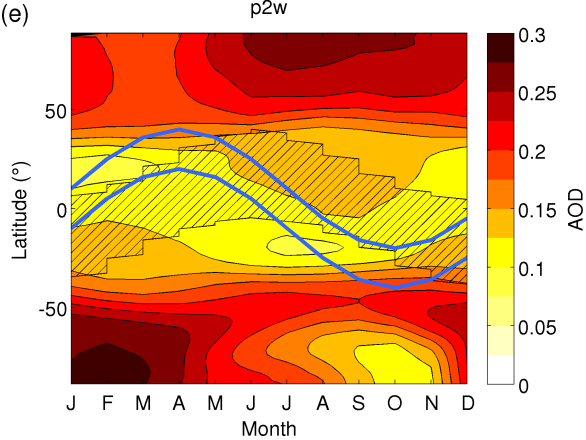

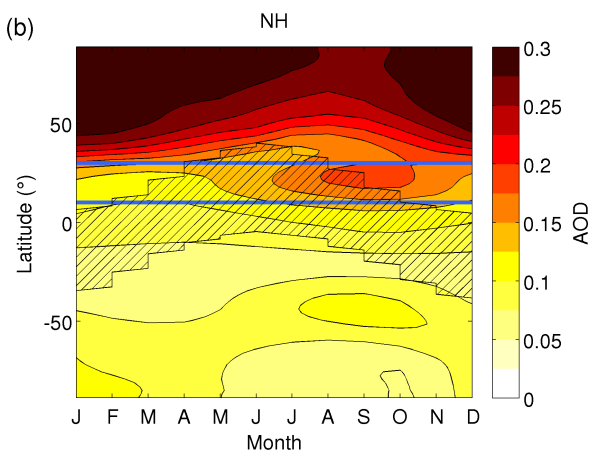

(d)
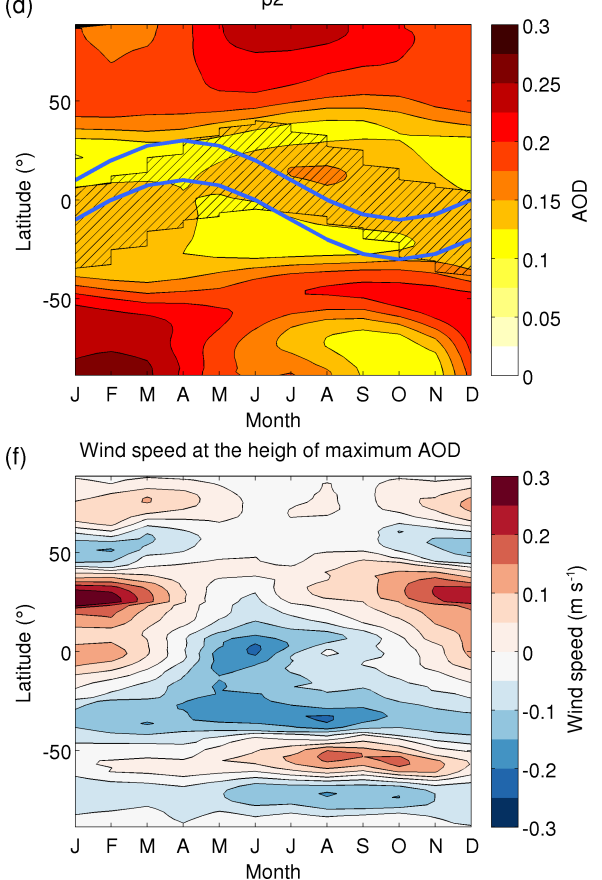

Figure 6. The zonal mean stratospheric AOD at $533 \mathrm{~nm}$ wavelength in (a) EQ, (b) NH, (c) NHSH, (d) p2, (e) p2w scenarios and the meridional wind component at the height of maximum AOD (positive values from south to north). The blue lines shows the boundaries of the injection area (two areas at c) NHSH) and the hatching shows latitudes which receive over $50 \%$ of monthly solar radiation.

lar direction transports $\mathrm{SO}_{2}$ and formed particles to higher latitudes and the subtropical AOD was relatively small at the spring months when the solar intensity was large (Fig. 6e and f).

These results show that trajectory analysis would be needed for more effective solar radiation management or when aiming radiative forcing more optimally to the specific latitudes. In addition, the radiative forcing of stratospheric sulfur injections is affected by many other factors. The hatched area in Fig. 6 shows the solar radiation in clearsky condition. The cloud cover is relatively smaller in the subtropics where the particles would then have a larger contribution to the radiation. In addition, the albedo of the surface and existing tropospheric aerosols should also be taken account when framing the optimal injection strategy. The solar forcing is also slightly larger in the Southern Hemisphere because the orbit of the Earth is closer to the Sun in boreal winter months.

Overall, these results show that the radiative forcing from the stratospheric sulfur injection can be concentrated to the midlatitudes with a small increase in the global mean radiative forcing when using a relatively simple injection strategy. As Fig. 6 shows, this impact would be possible to be increased by planning the injection strategy more specifically. However, the most optimal strategy and results depend on the objectives of the injections (Kravitz et al., 2016). In addition, here the latitudinal temporal dependence was chosen to be the only adjustable parameter while an optimal scenario would require the inclusion of also other adjustable parameters, e.g., the altitude of the injections and the composition of the injected aerosol. 
(a)

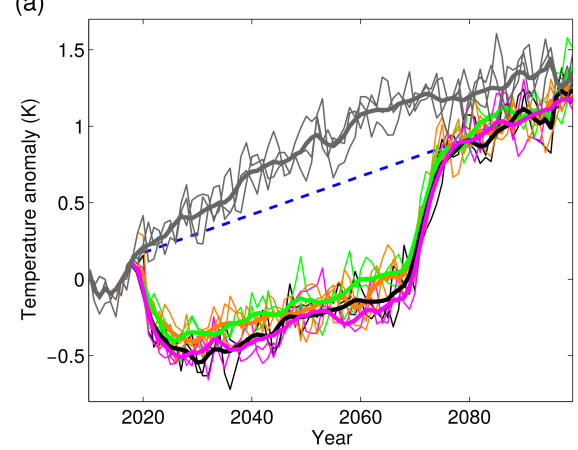

(b)

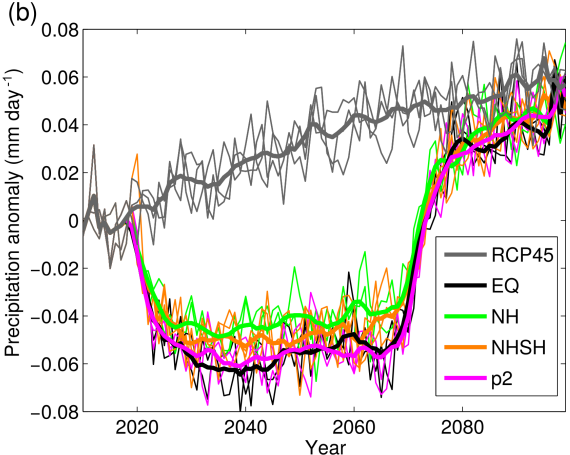

Figure 7. Global mean (a) temperature, (b) precipitation anomaly compared to the mean temperature for 2010-2020. The thick solid line shows the 5-year running ensemble mean values and each narrow line indicates the yearly mean values of one ensemble member. The blue dashed line shows the temperature after year 2020 according to the mean warming rate in EQ between years 2030 and 2070.

\subsection{Temperature and precipitation change - results of MPI-ESM simulations}

In this section we investigate how the aerosol radiative effects simulated for the different injection scenarios in Sect. 3.1 translate to global and regional climate impacts. The mean values for different scenarios were derived from ensembles of three simulations.

\subsubsection{The global mean temperature and precipitation response}

In SRM scenarios (EQ, NH, NHSH, p2 and p2w), stratospheric sulfur injections are started at full force $\left(5 \mathrm{Tg}(\mathrm{S}) \mathrm{yr}^{-1}\right)$ in year 2020 and suspended in year 2070 . Compared to the global mean $2 \mathrm{~m}$ temperature without SRM (RCP45), all scenarios lead to a fast and relatively similar global mean cooling after the injections were started (Fig. 7a). After that, the climate warms quickly due to the increased greenhouse gas concentrations in RCP4.5. In RCP45 scenario, between the years 2060-2070 the global $2 \mathrm{~m}$ temperature is $1.18 \mathrm{~K}$ warmer compared to years $2010-2020$. Compared to RCP45, the global mean temperature is -1.27 $( \pm 0.18),-1.13( \pm 0.13),-1.21( \pm 0.19),-1.34( \pm 0.14)$ and $-1.29( \pm 0.15) \mathrm{K}$ cooler in scenarios EQ, NH, NHSH, p2, and $\mathrm{p} 2 \mathrm{w}$ (not shown in the Fig. 7) between 2060-2070. Thus, the global mean temperature is close to the value during the 2010s. Scenario p2 leads to the largest global mean cooling, which is slightly larger (4\%) than in EQ as was expected based on simulations with ECHAM-HAMMOZ. Because SRM is turned on abruptly at full force in 2020, it would lead to a fast cooling. In the real world this kind of action is unlikely but based on the simulations it is plausible if needed for example to prevent a climate warming emergency (Kravitz et al., 2011).

After the very fast cooling in SRM scenarios, the climate starts to warm slowly when as the aerosol reaches its maximum cooling effect and the GHG concentrations in the atmosphere continue to increase. Even though this GHG-induced warming effect is similar in all SRM scenarios, the warming rate is clearly slower than in RCP4.5. Between the years 2030 and 2070 the warming rate is $1.95( \pm 0.68) \mathrm{K} / 100 \mathrm{yr}$ in RCP45 scenario, but in scenario EQ the warming rate is reduced to $1.25( \pm 0.55) \mathrm{K} / 100 \mathrm{yr}$. As the amount of injected sulfur does not change, the direct cooling effect of stratospheric sulfate particles does not increase during years 2030-2070. However, the ocean reacts slowly to the abrupt changes in the radiation and the changes in the atmospheric temperature (Giorgetta et al., 2013). Thus, the oceans are cooling in the beginning of SRM simulations, which leads to a slower warming compared to RCP4.5. In addition, the nonlinear climate feedbacks and especially changes in the ice albedo could slow down warming. Over the latitudes higher than $70^{\circ} \mathrm{N}$, the mean temperature is on the average still 0.6 $( \pm 0.5) \mathrm{K}$ cooler in SRM scenarios during the years 2060 2070 compared to the years 2010-2020, even though the global mean temperature was roughly compensated. Simultaneously, the sea ice cover is $7 \%$ larger. The cooling of the Arctic was not seen in previous studies in which solar radiation management has been investigated (Schmidt et al., 2012; Niemeier et al., 2013; Jones et al., 2016). The reason behind our simulation result is not totally clear. Section 3.1.2 showed that the AOD was relatively large at high latitudes, which would have an impact on the radiation in summer months. On the other hand, the total received energy in the Arctic area depends also on the energy transferred by the oceans and the atmosphere (Trenberth and Solomon, 1994). Figure 8a and b show that there is warming in the subpolar North Atlantic. In this area, the sea surface temperature (SST) increases by 2 $4 \mathrm{~K}$ in scenario EQ. On the other hand, there is a $1-2 \mathrm{~K}$ cooling in the SSTs in the Arctic Ocean. This indicates that there are changes in the ocean circulation. Since these patterns are seen also in scenario RCP45, they likely originate from in our reference years 2010-2020. The pattern of SST regions is similar to what is seen in CMIP5 RCP scenarios, where there was an amplified SST increase in the Nordic seas while in subpolar North Atlantic the warming rate was subdued com- 

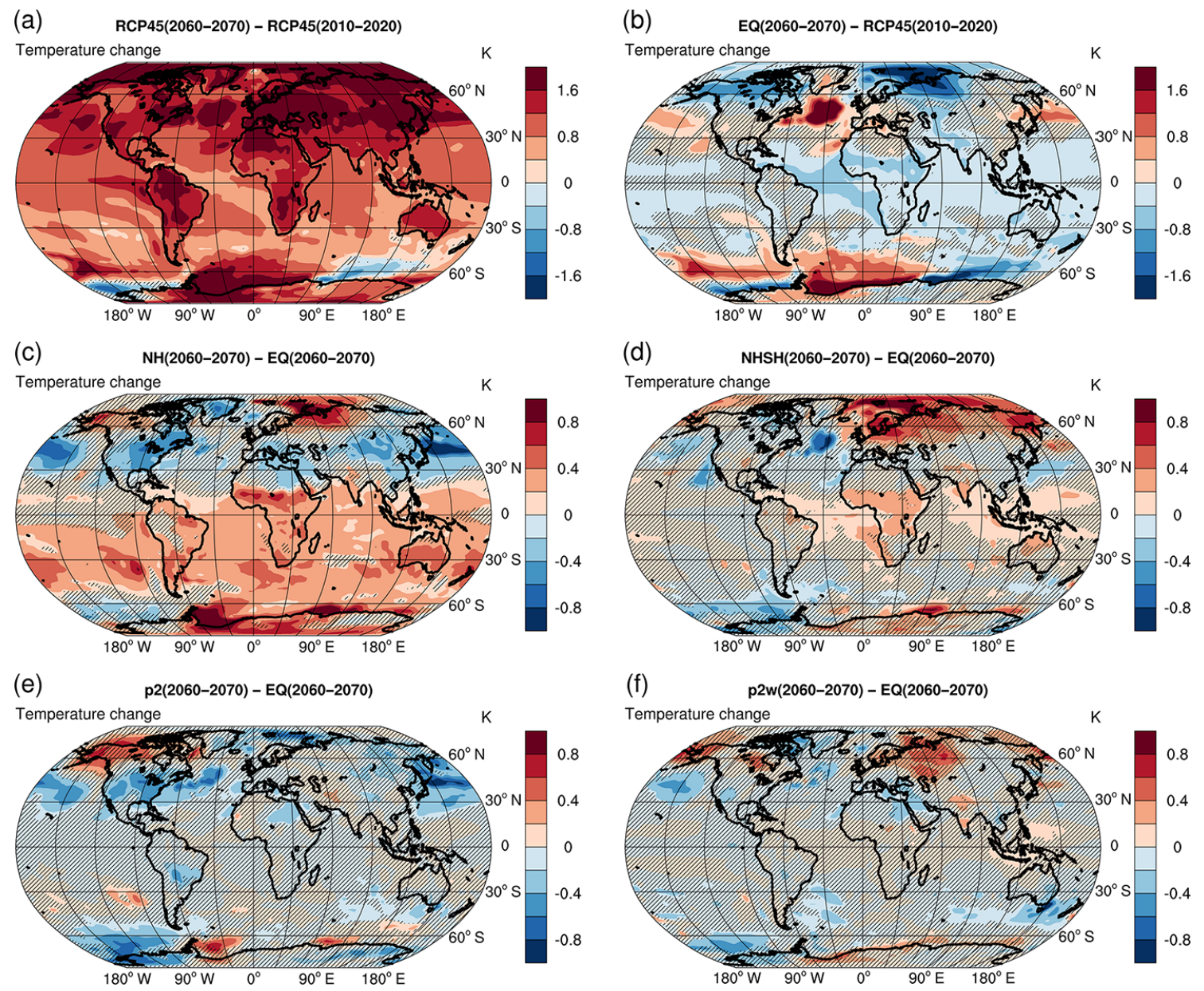

Figure 8. Temperature anomalies for (a) RCP45, (b) EQ, (c) NH, (d) NHSH, (e) p2 and (f) p2w. Anomalies in (a, b) are presented as differences between years 2060-2070 and 2010-2020. Anomalies in (c, d, e, f) are presented as a difference to EQ between years 20602070. The hatching indicates regions where the change of the temperature is not statistically significant at $95 \%$ level.

pared to the global average trend (Sgubin et al., 2017). However, investigating the changes in the ocean circulation is outside the scope of this study. Overall, different warming rates in SRM and RCP45 scenarios might also be affected by the asymmetric climate system response to the increase or decrease of forcings (Schaller et al., 2014). It has been shown that there is a slow decrease in temperature still decades after a decrease in shortwave radiation (Schaller et al., 2014). Kashimura et al. (2017) studied the GeoMIP G4 scenario in several models. Their study showed that the difference in the global mean temperature between the RCP 4.5 and SRM scenarios increased for 10-25 years after solar radiation management was started. Here the amount of injected sulfur was twice as large as in G4 and Kashimura et al. (2017), which can explain why here the temperature difference increased until SRM was suspended.

After the SRM is suspended in 2070 there is a very fast warming, called the termination effect of geoengineering (Jones et al., 2013). This fast warming in the first few years after the SRM is suspended is of the same magnitude as the cooling immediately after the sulfur injection is started. Thus, due to the different warming rates in RCP45 and SRM scenarios, the climate remains significantly cooler for decades after the SRM is suspended. If we make an assumption that the climate would warm after year 2020 at warming rate calculated from EQ from year 2030 to 2070 (blue dashed line in Fig. 8a), the global temperature would be at the same level after 2070 as it is in SRM scenarios after the rampdown period. All of the SRM scenarios start to approach the temperature of RCP45 a year after the suspension of SRM. However, up to the end of the simulation (years 2090-2099) the climate is still $(0.17-0.21) \mathrm{K}$ cooler in the SRM scenarios than for RCP45. In a multimodel experiment, Jones et al. (2013) studied the termination effect in GeoMIP G2 scenario, where the forcing from $1 \% \mathrm{yr}^{-1}$ increases in atmospheric $\mathrm{CO}_{2}$ concentration was compensated decreasing the solar constant and the SRM was suspended, similarly to this study, in 2070. Some of the models show still a cooler cli- 

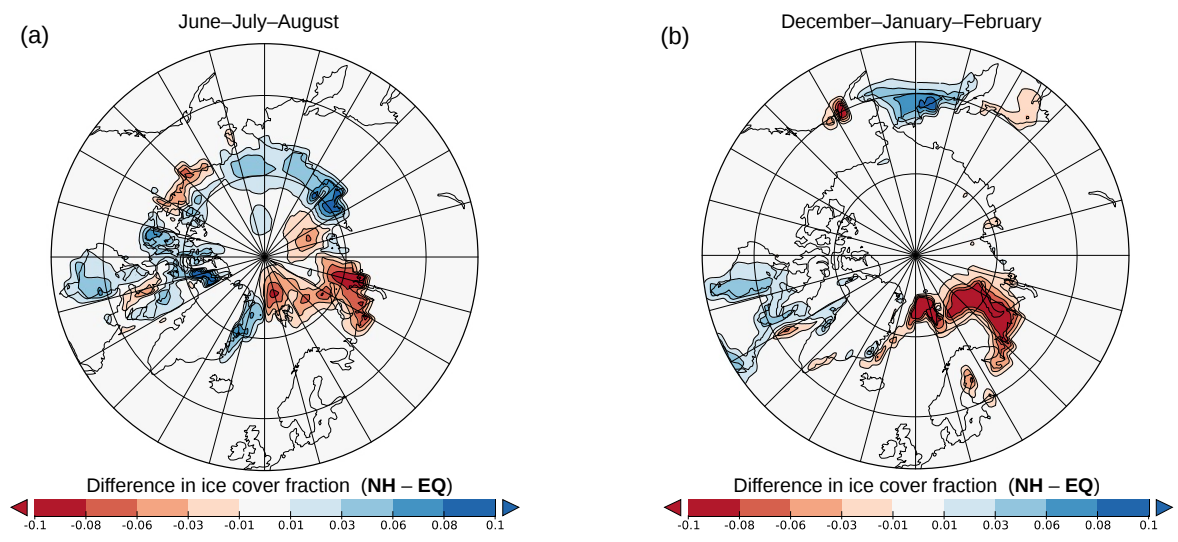

Figure 9. Difference in the ice cover fraction between scenarios NH and EQ in (a) June-July-August and (b) December-January-February. The blue regions show where the ice cover is larger in scenario NH than in EQ. The red regions shows where ice cover is smaller.

mate compared to the RCP4.5 scenario in year 2100, but in MPI-ESM temperatures were at the same level in both G2 and RCP4.5 scenarios. However, in here, scenarios that were based on the $\mathrm{G} 4$ scenario with $5 \mathrm{Tg}(\mathrm{S}) \mathrm{yr}^{-1}$ of injection climate were clearly overcooled after year 2020 and in most of the scenarios the climate was still cooler before SRM was suspended compared to years 2010-2020. In contrast, in scenario G2, simulated by Jones et al. (2013), the global mean temperature was kept at the same level, or slightly warmer after SRM was started in year 2020 and suspended in year 2070. Thus, in the scenarios here, ocean's heat uptake is reduced more than in G2.

Compensating the GHG-induced global warming using SRM has been suggested to lead to a reduction in the global mean precipitation (Kravitz et al., 2013b; Ferraro and Griffiths, 2016). This is also supported by our simulations. Immediately after the injection has been started, the global mean precipitation falls clearly under the level of year 2010 as can be seen in Fig. 7b. After a few years, the global mean precipitation starts to increase slowly (daily average precipitation $0.048 \mathrm{~mm} / 100 \mathrm{yr}$ in scenario EQ between the years from 2040 to 2069). The change rate of the precipitation is clearly smaller than in the RCP45 scenario (daily average precipitation $0.08 \mathrm{~mm} / 100 \mathrm{yr}$ ).

Between the years $2060-2070$, there is significantly less precipitation in all SRM scenarios than in 2010, even though temperatures are at the same level. Compared to years 2010-2020, the global mean precipitation has been changed by $+0.044( \pm 0.013),-0.051( \pm 0.013),-0.036$ $( \pm 0.013),-0.043( \pm 0.015),-0.054( \pm 0.011)$ and -0.05 $( \pm 0.014) \mathrm{mm} \mathrm{day}^{-1}$ in RCP45, EQ, NH, NHSH, p2 and p2w, respectively. Precipitation is thus more affected by the SRM than $\mathrm{CO}_{2}$. There are mainly two causes for the changes in the global mean precipitation. One cause is the temperature change (Bony et al., 2013; Ferraro et al., 2014; Kravitz et al., 2013b), which inflicts a feedback response due to the increased humidity in the atmosphere. The second mechanism is the temperature-independent atmospheric forcing (the change in the radiation between the surface and the top of the atmosphere) (Ferraro et al., 2014; Ferraro and Griffiths 2016). This is the rapid adjustment that occurs in a short timescale, when the change in the radiative balance is compensated by the changes in the latent and sensible heat fluxes (Bala et al., 2008). Increased $\mathrm{CO}_{2}$ concentration in the atmosphere produces the temperature-independent forcing and a decrease in precipitation. This is because $\mathrm{CO}_{2}$ affects the long-wave (LW) radiation in the whole troposphere. However, when the climate warms, water vapor concentration is increased in the atmosphere. This increase would lead to an increase in precipitation, which exceeds the decrease in precipitation due to the GHG radiative forcing. In SRM scenarios the GHG-induced warming from 2010 (slow response) is roughly compensated between the years 2060-2070 thus counterbalancing the temperature-dependent increase in precipitation. However, the temperature-independent fast response (decrease in precipitation) due to the increased $\mathrm{CO}_{2}$ concentration remains and is further amplified by the aerosol radiative effects. Aerosol particles both absorb radiation (which is then emitted as LW radiation) and reduce the SW radiation at surface. These effects have been suggested to lead to a drier climate (Ferraro and Griffiths, 2016).

\subsubsection{Spatial pattern of temperature and precipitation responses}

Next we concentrate on the regional climate impacts between years 2060 and 2070 before the SRM is suspended and where the global mean temperature does not change significantly. It has been suggested that global warming would lead to warmer climate in the Arctic and high latitudes than in low latitudes (Stocker et al., 2013). In our simulations there is over $2 \mathrm{~K}$ warming in the Arctic area between the years 2060 and 2070 compared to the 2010 temperatures in the RCP45 

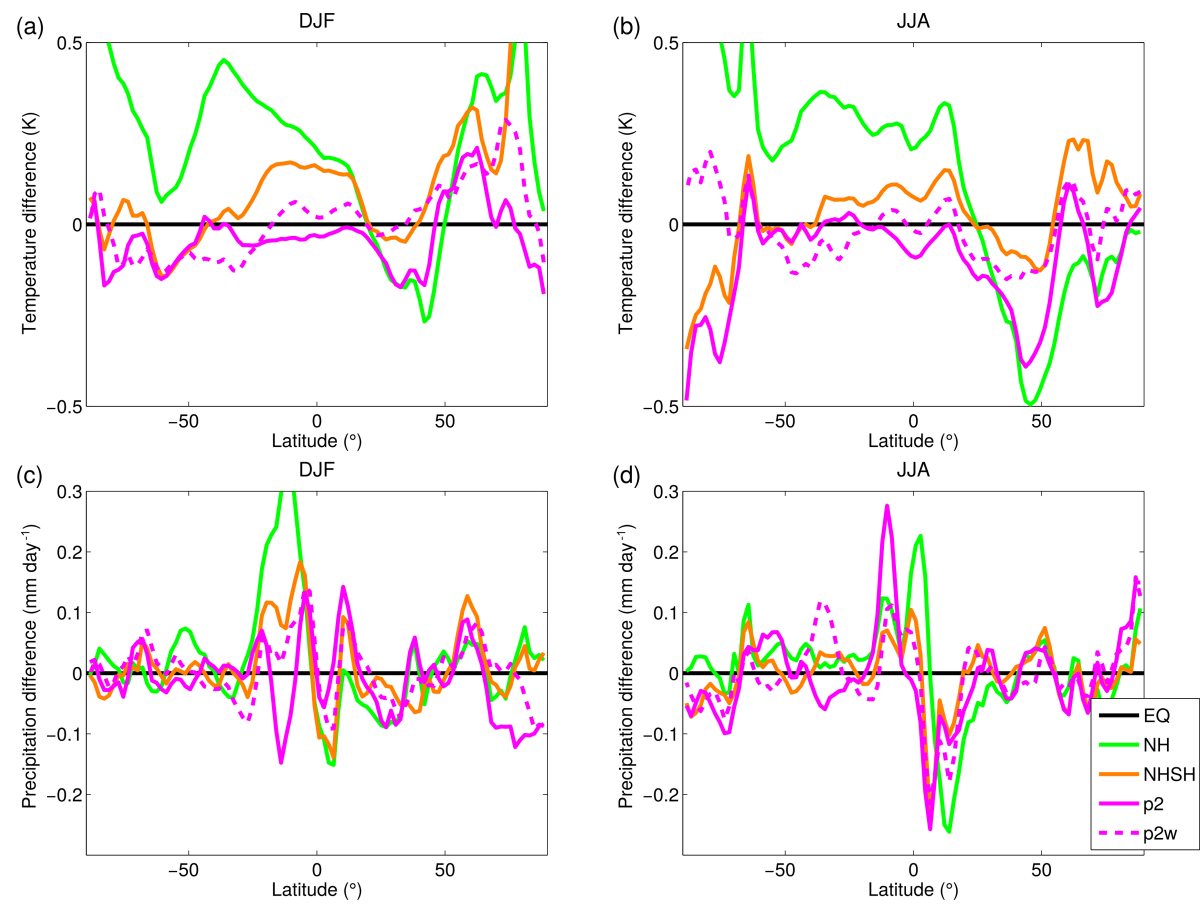

Figure 10. The zonal mean anomalies for the temperature in (a) December-January-February and (b) June-July-August and for precipitation in (c) December-January-February (d) June-July-August compared to scenario EQ.

scenario (Fig. 8a). If the global mean temperature change due to the increased GHG concentration is compensated by a relatively uniform reduction in the SW radiation (reduction in the solar constant), it has been shown to lead to warming in the high latitudes and cooling in the low latitudes compared to the temperature before the increase in GHG concentration and SRM (Kravitz et al., 2013c; Schmidt et al., 2012). Our results show that there will be cooling in the tropics and small warming at the midlatitudes in scenario EQ as indicated by earlier studies. However, there is also cooling at the Arctic (Fig. 8b), which was discussed in Sect. 3.2.1. This was likely mainly caused by changes in ocean circulations in 2010-2020 and not SRM scenarios studied here. Overall the size of the area of this Arctic cooling region is small compared to the regions in the midlatitudes, which have been warmed after the year 2020 .

Figure $8 \mathrm{c}-\mathrm{f}$ shows the difference between the alternative injection and scenario EQ. In scenarios $\mathrm{p} 2$ and $\mathrm{p} 2 \mathrm{w}$ there is less radiative forcing at the tropics and a larger radiative effect in the higher latitudes compared to scenario EQ. Although this does not translate directly to differences in the regional temperature near the surface as they are affected by other factors in the climate (Stocker et al., 2013), both p2 and $\mathrm{p} 2 \mathrm{w}$ show statistically significant cooling at the midlatitudes at North America and northern Pacific when compared to EQ. In these areas, scenario EQ leads to warming from years 2010 to 2020. As expected, the Equator was warmer in p2w compared to scenario EQ.
If the stratospheric sulfur injections were concentrated to the $\mathrm{NH}$, it would lead to a significant cooling in the northern midlatitudes compared to the injections to the EQ. However, the polar region north of Eurasia in $\mathrm{NH}$ is not cooler compared to the scenario EQ. The Arctic area is warmer than in scenario EQ especially in the boreal winter, when the cooling effect of the particles from the $\mathrm{NH}$ injections is weak (Fig. 9a). On the other hand, in the EQ scenario the mean global climate will be cooler, which can affect the Arctic temperatures through oceanic and atmospheric circulation. Figure 10 shows the difference in the Arctic sea ice cover between the EQ and $\mathrm{NH}$ scenarios in the boreal summer and winter. Scenario NH leads to a larger ice cover north of the North America and East Siberian Sea in the boreal summer and over the Atlantic and Pacific in the boreal winter. However, over the Barents and Kara seas there is more sea ice cover in the EQ scenario. This area is affected by the warm Gulf Stream and the Norwegian current. In the EQ scenario, the Atlantic SST is cooler than in scenario NH and sea ice cover in north of Eurasia is larger in scenario EQ also in the boreal summer months, when sulfate from NH scenario reflects radiation most efficiently. Thus, based on these results, the injections only to the Northern Hemisphere do not increase the yearly Arctic sea ice cover compared to the injections to Equator. A more detailed analysis would be required to generalize these findings; however, it is outside the scope of this study. Furthermore, it would be beneficial to repeat these scenarios also with other climate models to see whether 
the simulated response is robust across models. In scenario NHSH the Northern Hemisphere is generally cooled less by sulfate aerosols and thus the polar region is even warmer compared to NH and EQ. In addition in scenario NHSH, the tropical region is warmer compared to scenario EQ as was expected based on the distribution and magnitude of radiative forcing in Fig. 4.

Radiative forcing simulated and calculated by ECHAMHAMMOZ (see Sect. 3.1) showed that scenarios $\mathrm{p} 2$ and $\mathrm{p} 2 \mathrm{w}$ lead to an amplified seasonal effect of radiative forcing compared to EQ (Fig. 5c, d). Thus, p2w leads to a $0.05 \mathrm{~K}$ cooler climate in the Northern Hemisphere summer (JJA, Fig. 9b) and a $0.05 \mathrm{~K}$ cooler climate in the Southern Hemisphere summer (DJF, Fig. 9a) than EQ. The strong radiative forcing does not translate to large changes in temperature. For example, if we compare the cooling in different scenarios to the scenario without SRM (RCP45), compared to the simulation EQ the summertime forcing in scenario $\mathrm{p} 2 \mathrm{w}$ is $17 \%$ stronger in the Northern Hemisphere and $14 \%$ in the Southern Hemisphere. However, scenario p $2 \mathrm{w}$ leads to only $3 \%$ cooler climate in the Northern and Southern hemisphere summers than scenario EQ.

GHG-induced climate warming would increase the global mean precipitation as was seen in Sect. 3.2.1. Figure 11a shows that the yearly mean increase in precipitation is largest at the equatorial Pacific. This is in good agreement with intergovernmental panel on climate change (IPCC) estimations (Stocker et al., 2013). These regions correspond to the spatial maximum of sea surface temperature warming at equatorial Pacific (Xie et al., 2010). Similarly SST warming exceeds the mean SST warming at northern Pacific and Atlantic where precipitation has increased. It has also been shown that $P-E$ (Precipitation-Evaporation) will become more intense when climate warms (Seager et al., 2010), which will cause wet areas to become wetter but also drying in the subtropical regions such as Mediterranean, southern part of Africa and Australia. In the EQ scenario, precipitation is decreased in the equatorial Pacific where SST is mainly decreased from the years 2010 to 2020 (Fig. 11b). The only exception is the eastern part of equatorial Pacific where there has been slight warming in SST, which results in increased precipitation. In addition in EQ scenario, $P-E$ is not significantly changed in the subtropical regions and the precipitation is at the same level as in 2010. However, there is clearly less precipitation in the northern part of South America in both scenarios RCP45 and EQ. This might be due to the change in the Atlantic SST gradient (similar in RCP45 and EQ) and its influence to ITCZ (Haywood et al., 2013). This will lead to reduced moisture, which is transported from the Atlantic. If sulfur is injected to the Northern Hemisphere (scenario NH), the change in the Atlantic SST gradient is opposite compared to scenario RCP45 and EQ, which leads to increased precipitation in northern South America and drying of Sahel (Fig. 11c).
Overall regional precipitation changes between the studied injection scenarios are not statistically significant. All alternative injection scenarios lead to a slight decrease in the Atlantic SST gradient, which leads to drier Sahel simultaneously to increased precipitation in the southern equatorial Atlantic compared to scenario EQ. In addition, equatorial Pacific SST is decreased relatively more compared to scenario $\mathrm{EQ}$, which leads to a larger reduction in precipitation especially in scenarios $\mathrm{p} 2$ and $\mathrm{p} 2 \mathrm{w}$. The seasonal zonal mean precipitation response is slightly different in scenarios EQ and p2 (Fig. 10c, d).

For JJA there is a relatively large difference in the zonal mean anomalies of precipitation at tropics between the EQ and p2 scenarios (Fig. 10c, d). In both case there will be less precipitation compared to the reference years (2010-2020), but the decrease is clearly larger in the northern low latitudes in $\mathrm{p} 2$ than in EQ and vice versa at the southern low latitudes. Sobel and Camargo (2011) showed that an increase in the summer hemisphere SST and a decrease in the winter hemisphere SST leads to the strengthening of easterly trade winds in the winter subtropics and to their weakening in the summer subtropics. This is further associated to Hadley cell circulation and ITCZ, which strongly affect the precipitation response in the tropics. As has been shown, p2 leads to a larger cooling effect at the summer hemisphere and a weaker cooling effect in the winter hemisphere when compared to scenario EQ.

\section{Summary and conclusions}

Here we used an atmosphere-only general circulation model coupled to an aerosol model to simulate the radiative properties of different stratospheric sulfur injection strategies as opposed injecting sulfur only to the Equator. In the second part of the study, we examined how the radiative forcings from different injection scenarios translate to temperature and precipitation impacts by using the Max Planck Institute Earth System Model. We estimated how different emission areas of stratospheric sulfur could be used to prevent the overcooling of the tropics and undercooling of the midlatitudes and the Arctic without a decrease in the global mean radiative forcing of the stratospheric sulfur injections.

In all simulated scenarios, $5 \mathrm{Tg}(\mathrm{S}) \mathrm{yr}^{-1}$ of $\mathrm{SO}_{2}$ was injected into $20^{\circ}$ latitude wide band ( 2 bands in NHSH) and the resulting radiative and climate effects were compared to those in a scenario where sulfur is injected only above the Equator. According to our aerosol microphysical simulations by GCM, it would be possible to maintain as large a global cooling effect as by injecting sulfur only on the Equator while concentrating the cooling effect more to the midlatitudes than tropics. This could be achieved if the sulfur injection area is changed during the year. Such a scenario was $\mathrm{p} 2 \mathrm{w}$, where the injection area changed from its northernmost position $\left(40-20^{\circ} \mathrm{N}\right)$ at April to the southernmost posi- 

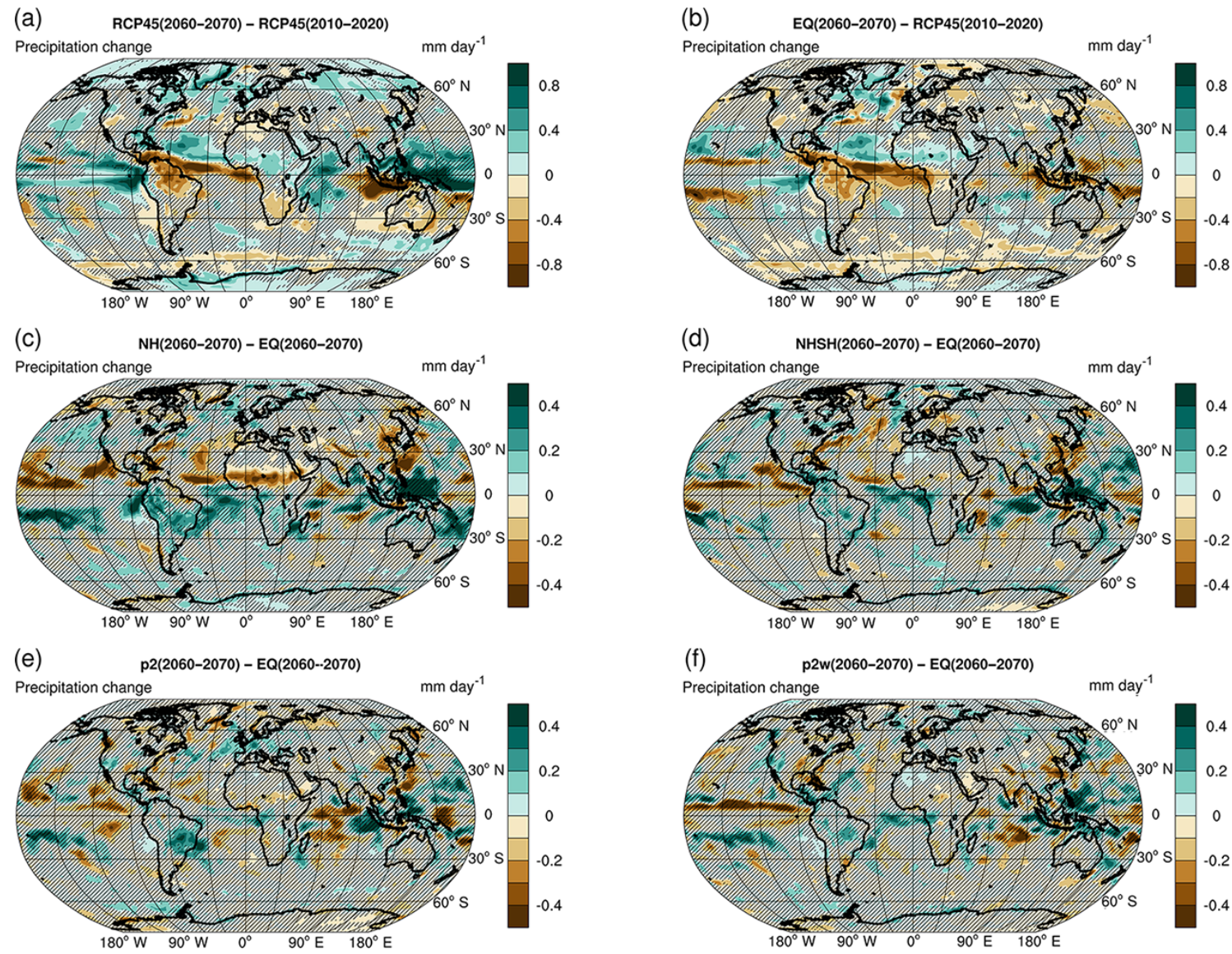

Figure 11. The precipitation anomalies for (a) RCP45, (b) EQ, (c) NH, (d) NHSH, (e) p2 and (f) p2w. Anomalies in (a, b) are presented as the differences between years 2060-2070 and 2010-2020. Anomalies in (c, d, e, f) are presented as the difference to EQ between years 2060-2070. The hatching indicates regions where the change of precipitation is not statistically significant at $95 \%$ level.

tion $\left(20-40^{\circ} \mathrm{S}\right)$ at October. In this scenario the mean radiative forcing was $27 \%$ smaller between $20^{\circ} \mathrm{N}$ and $20^{\circ} \mathrm{S}$ latitudes and outside this area $15 \%$ larger than in the simulation $\mathrm{EQ}$, which assumed fixed continuous injection area over the Equator $\left(10^{\circ} \mathrm{S}-10^{\circ} \mathrm{N}\right)$. If the injection area is changed similarly but between $30^{\circ} \mathrm{N}$ and $30^{\circ} \mathrm{S}$ latitudes (p2), the global mean shortwave radiative forcing was $3 \%$ larger than injecting sulfur only at the Equator (EQ). More of the injected sulfur was located at the summer hemisphere in $\mathrm{p} 2 \mathrm{w}$ scenario compared to EQ. Thus, the radiative forcing was relatively larger in the summer hemisphere $(17 \%$ in the Northern Hemisphere and $14 \%$ in the Southern Hemisphere) and relatively weaker in the winter hemispheres (14\% in the Northern Hemisphere and $16 \%$ in the Southern Hemisphere) compared to EQ.

Based on this study the effectiveness of a seasonally changed injection area depends on the seasonality (the intensity) of solar radiation, oxidation of $\mathrm{SO}_{2}$ (which depends on availability of $\mathrm{OH}$ ) and the lifetime of sulfate particles. Our simulations indicate that the global mean radiative forcing of the aerosol was not significantly increased in any of our sim- ulations compared to the equatorial injection scenario EQ. However, the scenarios studied here are only the first step towards more optimal injection scenarios. A full optimization would require a more detailed analysis of the incoming and the reflected solar radiation, atmospheric circulation and how it is affected by sulfur fields as well as aerosol microphysics and chemistry. Overall, however, the results of this study already show the potential of time-varying injection scenarios.

Scenarios simulated by ESM were based on GeoMIP G4 scenarios, where the aerosols injection $\left(5 \mathrm{Tg}(\mathrm{S}) \mathrm{yr}^{-1}\right.$ instead of $2.5 \mathrm{Tg}(\mathrm{S}) \mathrm{yr}^{-1}$ in G4) is started at full force in 2020 and then suspended in 2070. Solar radiation management scenarios studied here led to a cooling of 1.13-1.34 K. ESM simulations also showed that by changing the injection area during the year, it would be possible to get more cooling to the midlatitudes and less cooling in the tropics compared to injections only to the Equator. This can be achieved by injecting sulfur only to $30-10^{\circ} \mathrm{N}$ and $10-30^{\circ} \mathrm{S}$ latitudes (NHSH). However, then the climate cooling was $15 \%$ smaller than in scenarios where the injection area was varying during the year. These injection strategies could be used to avoid a re- 
duction of the meridional temperature gradient, which has been seen in many previous studies where SRM have been investigated (Schmidt et al., 2012; Kravitz et al., 2016). The global mean precipitation was clearly decreased in all of our SRM simulations even though the temperature changes were roughly compensated. This is consistent with earlier studies. When looking at seasonal values, different injection scenarios led to different results especially at the tropics.

Even though seasonally varying injection areas could allow for more control over the geographic pattern of the radiative forcing compared to equatorial injections, this might not lead to large differences in regional climate impacts. This is because the heat transport via the oceans and the atmosphere greatly smooth out the impacts from spatially inhomogeneous aerosol forcing. In addition, due to the atmospheric transport, it is impossible to concentrate the radiative forcing from sulfur injections to any limited area. Thus, stratospheric sulfur injections are not an effective method with which to aim for certain regional temperature or precipitation impacts. Despite this, our results indicate that seasonally changing injection areas could resolve some of the spatial inhomogeneities resulting from more commonly studied equatorial injections.

Code and data availability. The data from the model simulations and implemented model codes are available from the authors upon request.

Competing interests. The authors declare that they have no conflict of interest.

Acknowledgements. This work was supported by Academy of Finland's Centre of Excellence Programme (decision 272041), the Academy of Finland's Academy Research Fellow positions (decisions 250348 and 283031) and European Research Council (ERC Consolidator Grant 646857). The authors wish to thank T. Kühn for discussions related to using coupled models. The ECHAMHAMMOZ model is developed by a consortium composed of ETHZ, Max Planck Institut für Meteorologie, Forschungszentrum Jülich, University of Oxford and the Finnish Meteorological Institute and managed by the Center of Climate Systems Modeling (C2SM) at ETHZ.

Edited by: B. Kravitz

Reviewed by: three anonymous referees

\section{References}

Aswathy, V. N., Boucher, O., Quaas, M., Niemeier, U., Muri, H., Mülmenstädt, J., and Quaas, J.: Climate extremes in multi-model simulations of stratospheric aerosol and marine cloud brightening climate engineering, Atmos. Chem. Phys., 15, 9593-9610, https://doi.org/10.5194/acp-15-9593-2015, 2015.
Bala, G., Duffy, P. B., and Taylor, K. E.: Impact of geoengineering schemes on the global hydrological cycle, P. Natl. Acad. Sci. USA, 105, 7664-7669, https://doi.org/10.1073/pnas.0711648105, 2008.

Bony, S., Bellon, G., Klocke, D., Sherwood, S., Fermepin, S., and Denvil, S.: Robust direct effect of carbon dioxide on tropical circulation and regional precipitation, Nat. Geosci., 6, 447-451, 2013.

Bergman, T., Kerminen, V.-M., Korhonen, H., Lehtinen, K. J., Makkonen, R., Arola, A., Mielonen, T., Romakkaniemi, S., Kulmala, M., and Kokkola, H.: Evaluation of the sectional aerosol microphysics module SALSA implementation in ECHAM5HAM aerosol-climate model, Geosci. Model Dev., 5, 845-868, https://doi.org/10.5194/gmd-5-845-2012, 2012.

Dentener, F., Kinne, S., Bond, T., Boucher, O., Cofala, J., Generoso, S., Ginoux, P., Gong, S., Hoelzemann, J. J., Ito, A., Marelli, L., Penner, J. E., Putaud, J.-P., Textor, C., Schulz, M., van der Werf, G. R., and Wilson, J.: Emissions of primary aerosol and precursor gases in the years 2000 and 1750 prescribed data-sets for AeroCom, Atmos. Chem. Phys., 6, 43214344, https://doi.org/10.5194/acp-6-4321-2006, 2006.

English, J. M., Toon, O. B., and Mills, M. J.: Microphysical simulations of sulfur burdens from stratospheric sulfur geoengineering, Atmos. Chem. Phys., 12, 4775-4793, https://doi.org/10.5194/acp-12-4775-2012, 2012.

Feichter, J., Kjellsttrom, E., Rodhe, H., Dentener, F., Lelieveldi, J., and Roelofs, G.-J.: Simulation of the tropospheric sulfur cycle in a global climate model, Atmos. Environ., 30, 1693-1707, https://doi.org/10.1016/1352-2310(95)00394-0, 1996.

Ferraro, A. J. and Griffiths, H. G.: Quantifying the temperatureindependent effect of stratospheric aerosol geoengineering on global-mean precipitation in a multi-model ensemble, Environ. Res. Lett., 11, 034012, https://doi.org/10.1088/17489326/11/3/034012, 2016.

Ferraro, A. J., Highwood, E. J., and Charlton-Perez, A. J.: Weakened tropical circulation and reduced precipitation in response to geoengineering, Environ. Res. Lett., 9, 014001, https://doi.org/10.1088/1748-9326/9/1/014001, 2014.

Giorgetta, M., Jungclaus, J., Reick, C. H., Legutke, S., Bader, J., Böttinger, M., Brovkin, V., Crueger, T., Esch, M., Fieg, K., Glushak, K., Gayler, V., Haak, H., Hollweg, H.-D., Ilyina, T., Kinne, S., Kornblueh, L., Matei, D., Mauritsen, T., Mikolajewicz, U., Mueller, W., Notz, D., Pithan, F., Raddatz, T., Rast, S., Redler, R., Roeckner, E., Schmidt, H., Schnur, R., Segschneider, J., Six, K. D., Stockhause, M., Timmreck, C., Wegner, J., Widmann, H., Wieners, K.-H., Claussen, M., Marotzke, J., and Stevens, B.: Climate and carbon cycle changes from 1850 to 2100 in MPI-ESM simulations for the coupled model intercomparison project phase 5, J. Adv. Model. Earth Syst., 5, 572-597, https://doi.org/10.1002/jame.20038, 2013.

Haywood, J. M., Jones, A., Bellouin, N., and Stephenson, D.: Asymmetric forcing from stratospheric aerosols impacts Sahelian rainfall, Nature Clim. Change, 3, 660-665, https://doi.org/10.1038/nclimate1857, 2013.

Heckendorn, P., Weisenstein, D., Fueglistaler, S., Luo, B. P., Rozanov, E., Schraner, M., Thomason, L. W., and Peter, T.: The impact of geoengineering aerosols on stratospheric temperature and ozone, Environ. Res. Lett., 4, 045108, https://doi.org/10.1088/1748-9326/4/4/045108, 2009. 
Ilyina, T., Six, K. D., Segschneider, J., Maier-Reimer, E., Li, H., and Nunez-Riboni, I.: Global ocean biogeochemistry model HAMOCC: Model architecture and performance as component of the MPI-Earth System Model in different CMIP5 experimental realizations, J. Adv. Model. Earth Syst., 5, 287-315, https://doi.org/10.1029/2012MS000178, 2013.

Jones, A., Haywood, J., Boucher, O., Kravitz, B., and Robock, A.: Geoengineering by stratospheric $\mathrm{SO}_{2}$ injection: results from the Met Office HadGEM2 climate model and comparison with the Goddard Institute for Space Studies ModelE, Atmos. Chem. Phys., 10, 5999-6006, https://doi.org/10.5194/acp10-5999-2010, 2010.

Jones, A., Haywood, J. M., Alterskjær, K., Boucher, O., Cole, J. N. S., Curry, C. L., Irvine, P. J., Ji, D., Kravitz, B., Kristjánsson, J. E., Moore, J. C., Niemeier, U., Robock, R., Schmidt, H. Singh, H., Tilmes, S., Watanabe, S., and Yoon, J. H.: The impact of abrupt suspension of solar radiation management (termination effect) in experiment G2 of the Geoengineering Model Intercomparison Project (GeoMIP), J. Geophys. Res., 118, 9743-9752, https://doi.org/10.1002/jgrd.50762, 2013.

Jones, A. C., Haywood, J. M., and Jones, A.: Climatic impacts of stratospheric geoengineering with sulfate, black carbon and titania injection, Atmos. Chem. Phys., 16, 2843-2862, https://doi.org/10.5194/acp-16-2843-2016, 2016.

Jungclaus, J. H., Fischer, N., Haak, H., Lohmann, K., Marotzke, J., Matei, D., Mikolajewicz, U., Notz, D., and von Storch, J.-S.: Characteristics of the ocean simulations in MPIOM, the ocean component of the MPI Earth System Model, J. Adv. Model. Earth Syst., 5, 422-446, https://doi.org/10.1002/jame.20023, 2013.

Kashimura, H., Abe, M., Watanabe, S., Sekiya, T., Ji, D., Moore, J. C., Cole, J. N. S., and Kravitz, B.: Shortwave radiative forcing, rapid adjustment, and feedback to the surface by sulfate geoengineering: analysis of the Geoengineering Model Intercomparison Project G4 scenario, Atmos. Chem. Phys., 17, 3339-3356, https://doi.org/10.5194/acp-17-3339-2017, 2017.

Kinne, S., O’Donnell, D., Stier, P., Kloster, S., Zhang, K., Schmidt, H., Rast, S., Giorgetta, M., Eck, T. F., and Stevens, B.: MAC-v1: A new global aerosol climatology for climate studies, J. Adv. Model. Earth Syst., 5, 704-740, https://doi.org/10.1002/jame.20035, 2013.

Kokkola, H., Korhonen, H., Lehtinen, K. E. J., Makkonen, R., Asmi, A., Järvenoja, S., Anttila, T., Partanen, A.-I., Kulmala, M., Järvinen, H., Laaksonen, A., and Kerminen, V.-M.: SALSA - a Sectional Aerosol module for Large Scale Applications, Atmos. Chem. Phys., 8, 2469-2483, https://doi.org/10.5194/acp-8-24692008, 2008.

Kravitz, B., Robock, A., Boucher, O., Schmidt, H., Taylor, K. E., Stenchikov, G., and Schulz, M.: The Geoengineering Model Intercomparison Project (GeoMIP), Atmos. Sci. Lett., 12, 162167, https://doi.org/10.1002/asl.316, 2011.

Kravitz, B., Robock, A., Forster, P. M., Haywood, J. M., Lawrence, M. G., and Schmidt, H.: An overview of the Geoengineering Model Intercomparison Project (GeoMIP), J. Geophys. Res., 118, 13103-13107, https://doi.org/10.1002/2013JD020569, 2013a.

Kravitz, B., Rasch, P. J., Forster, P. M., Andrews, T., Cole, J. N. S., Irvine, P. J., Ji, D., Kristjánsson,J. E., Moore, J. C., Muri, H., Niemeier, U., Robock, A., Singh, B., Tilmes, S., Watanabe, S., and Yoon, J.-H.: An energetic perspective on hydro- logical cycle changes in the Geoengineering Model Intercomparison Project, J. Geophys. Res.-Atmos., 118, 13087-13102, https://doi.org/10.1002/2013JD020502, 2013b.

Kravitz, B., Caldeira, K., Boucher, O., Robock, A., Rasch, P. J., Alterskjær, K., Karam, D., B., Cole, J. N. S., Curry, C. L., Haywood, J. M., Irvine, P. J., Ji, D., Jones, A., Kristjánsson, J. E., Lunt, D. J., Moore, J. C., Niemeier, U., Schmidt, H., Schulz, M., Singh, B., Tilmes, S., Watanabe, S., Yang, S., and Yoon, J.-H.: Climate model response from the Geoengineering Model Intercomparison Project (GeoMIP), J. Geophys. Res.-Atmos., 118, 8320-8332, https://doi.org/10.1002/jgrd.50646, $2013 \mathrm{c}$.

Kravitz, B., MacMartin, D. G., Wang, H., and Rasch, P. J.: Geoengineering as a design problem, Earth Syst. Dynam., 7, 469-497, https://doi.org/10.5194/esd-7-469-2016, 2016.

Laakso, A., Kokkola, H., Partanen, A.-I., Niemeier, U., Timmreck, C., Lehtinen, K. E. J., Hakkarainen, H., and Korhonen, H.: Radiative and climate impacts of a large volcanic eruption during stratospheric sulfur geoengineering, Atmos. Chem. Phys., 16, 305-323, https://doi.org/10.5194/acp-16-305-2016, 2016.

MacMartin, D. G., Keith, D. W., Kravitz, B., and Caldeira, K.: Management of trade-offs in geoengineering through optimal choice of non-uniform radiative forcing, Nat. Clim. Change, 3, 365-368, https://doi.org/10.1038/nclimate1722, 2013.

McCusker, K. E., Battisti, D. S., and Bitz, C. M.: The climate response to stratospheric sulfate injections and implications for addressing climate emergencies, J. Climate, 25, 3096-3116, https://doi.org/10.1175/JCLI-D-11-00183.1, 2012.

Modak, A. and Bala, G.: Sensitivity of simulated climate to latitudinal distribution of solar insolation reduction in solar radiation management, Atmos. Chem. Phys., 14, 7769-7779, https://doi.org/10.5194/acp-14-7769-2014, 2014.

Moss, R. H., Edmonds, J. A., Hibbard, K. A., Manning, M. R., Rose, S. K., van Vuuren, D. P., Carter, T. R., Emori, S., Kainuma, M., Kram, T., Meehl, G. A., Mitchell, J. F. B., Nakicenovic, N., Riahi, K., Smith, S. J., Stouffer, R. J., Thomson, A. M., Weyant, J. P., and Wilbanks, T. J.: The next generation of scenarios for climate change research and assessment, Nature, 463, 747-756, https://doi.org/10.1038/nature08823, 2010.

Niemeier, U., Schmidt, H., and Timmreck, C.: The dependency of geoengineered sulfate aerosol on the emission strategy, Atmos. Sci. Lett., 12, 189-194, https://doi.org/10.1002/asl.304, 2011.

Niemeier, U., Schmidt, H., Alterskjær, K., and Kristjánsson, J. E.: Solar irradiance reduction via climate engineering: Impact of different techniques on the energy balance and the hydrological cycle, J. Geophys. Res., 118, 11905-11917, https://doi.org/10.1002/2013JD020445, 2013.

Pierce, J. R., Weisenstein, D. K., Heckendorn, P., Peter, T., and Keith, D. W.: Efficient formation of stratospheric aerosol for climate engineering by emission of condensable vapor from aircraft, Geophys. Res. Lett., 37, L18805, https://doi.org/10.1029/2010GL043975, 2010.

Pope, F. D., Braesicke, P., Grainger, R. G., Kalberer, M., Watson, I. M., Davidson, P. J., and Cox, R. A.: Stratospheric aerosol particles and solar-radiation management, Nature Clim. Change, 2, 713-719, https://doi.org/10.1038/nclimate1528, 2012.

Reick, C., Raddatz, T. V., Brovkin, V., and Gayler, V.: The representation of natural and anthropogenic land cover change in MPI-ESM, J. Adv. Model. Earth Syst., 5, 459-482, https://doi.org/10.1002/jame.20022, 2013. 
Robock, A., Oman, L., and Stenchikov, G. L.: Regional climate responses to geoengineering with tropical and Arctic $\mathrm{SO}_{2}$ injections, J. Geophys. Res., 113, D16101, https://doi.org/10.1029/2008JD010050, 2008.

Royal Society: Geoengineering the climate - Science, governance and uncertainty, RS Policy document 10/09, London, 2009.

Schaller, N., Sedlácek, J., and Knutti, R.: The asymmetry of the climate system's response to solar forcing changes and its implications for geoengineering scenarios, J. Geophys. Res.-Atmos., 119, 5171-5184, https://doi.org/10.1002/2013JD021258, 2014.

Schmidt, H., Alterskjær, K., Bou Karam, D., Boucher, O., Jones, A., Kristjánsson, J. E., Niemeier, U., Schulz, M., Aaheim, A., Benduhn, F., Lawrence, M., and Timmreck, C.: Solar irradiance reduction to counteract radiative forcing from a quadrupling of $\mathrm{CO}_{2}$ : climate responses simulated by four earth system models, Earth Syst. Dynam., 3, 63-78, https://doi.org/10.5194/esd-3-632012, 2012.

Seager, R., Naik, N., and Vecchi, G. A.: Thermodynamic and dynamic mechanisms for large-scale changes in the hydrological cycle in response to global warming, J. Climate, 23, 4651-4668, https://doi.org/10.1175/2010JCLI3655.1, 2010.

Sgubin, G., Swingedouw, D., Drijfhout, S., Yannick Mary, Y., and Bennabi, A.: Abrupt cooling over the North Atlantic in modern climate models, Nat. Commun., 8, https://doi.org/10.1038/ncomms14375, 2017.

Sobel, A. H. and Camargo, S. J.: Projected future changes in tropical summer climate, J. Climate, 24, 473-487, 2011.

Stocker, T., Qin, D., Plattner, G.-K., Tignor, M., Allen, S., Boschung, J., Nauels, A., Xia, Y., Bex, V., and Midgley, P.: The Physical Science Basis. Working Group I Contribution to the Fifth Assessment Report of the Intergovernmental Panel on Climate Change, in: IPCC, 2013: Climate Change 2013, Cambridge University Press, Cambridge, UK and New York, NY, USA, 2013.

Stevens, B., Giorgetta, M., Esch, M., Mauritsen, T., Crueger, T., Rast, S., Salzmann, M., Schmidt, H., Bader, J., Block, K., Brokopf, R., Fast, I., Kinne, S., Kornblueh, L., Lohmann, U., Pincus, R., Reichler, T., and Roeckner, E.: The atmospheric component of the MPI-M Earth System Model: ECHAM6, J. Adv. Model. Earth Syst., 5, 1-27, https://doi.org/10.1002/jame.20015, 2013.
Taylor, K. E., Stouffer, R. J., and Meehl, G. A.: A summary of the CMIP5 experiment design, World Climate Research Programme (WCRP), available at: http://cmip-pcmdi.llnl.gov/cmip5/docs/ Taylor_CMIP5_design.pdf (last access: April 2016), 2008.

Tilmes, S., Mills, M. J., Niemeier, U., Schmidt, H., Robock, A., Kravitz, B., Lamarque, J.-F., Pitari, G., and English, J. M.: A new Geoengineering Model Intercomparison Project (GeoMIP) experiment designed for climate and chemistry models, Geosci. Model Dev., 8, 43-49, https://doi.org/10.5194/gmd-8-43-2015, 2015.

Trenberth, K. E. and Solomon, A.: The global heat balance: heat transports in the atmosphere and ocean, Clim. Dynam., 10, 107134, https://doi.org/10.1007/BF00210625, 1994.

van Vuuren, D. P., Edmonds, J., Kainuma, M., Riahi, K., Thomson, A., Hibbard, K., Hurtt, G. C., Kram, T., Krey, V., Lamarque, J.-F., Masui, T., Meinshausen, M., Nakicenovic, N., Smith, S. J., and Rose, S. K.: The representative concentration pathways: an overview, Climatic Change, 109, 5-31, https://doi.org/10.1007/s10584-011-0148-z, 2011.

Volodin, E. M., Kostrykin, S. V., and Ryaboshapko, A. G.: Climate response to aerosol injection at different stratospheric locations, Atmos. Sci. Lett., 12, 381-385, https://doi.org/10.1002/asl.351, 2011.

Xie, S., Deser, C., Vecchi, G., Ma, J., Teng, H., and Wittenberg, A.: Global Warming Pattern Formation: Sea Surface Temperature and Rainfall, J. Climate, 23, 966-986, https://doi.org/10.1175/2009JCLI3329.1, 2010.

Yu, X., Moore, J. C., Cui, X., Rinke, A., Ji, D., Kravitz, B., and Yoon, J.-H.: Impacts, effectiveness and regional inequalities of the GeoMIP G1 to G4 solar radiation management scenarios, Global Planet. Change, 129, 10-22, https://doi.org/10.1016/j.gloplacha.2015.02.010, 2015.

Zhang, K., O’Donnell, D., Kazil, J., Stier, P., Kinne, S., Lohmann, U., Ferrachat, S., Croft, B., Quaas, J., Wan, H., Rast, S., and Feichter, J.: The global aerosol-climate model ECHAM-HAM, version 2: sensitivity to improvements in process representations, Atmos. Chem. Phys., 12, 8911-8949, https://doi.org/10.5194/acp-12-8911-2012, 2012. 